\title{
Biological role of metabolic reprogramming of cancer cells during epithelial-mesenchymal transition (Review)
}

\author{
MINGZHE LI ${ }^{1 *}, \mathrm{XIN} \mathrm{BU}^{1 *}$, BOLEI CAI ${ }^{2 *}, \mathrm{PING} \mathrm{LIANG}^{3}, \mathrm{KAI} \mathrm{LI}^{4}$, \\ $\mathrm{XUAN}_{\mathrm{QU}}{ }^{5}$ and LIANGLIANG SHEN ${ }^{1}$ \\ ${ }^{1}$ The State Key Laboratory of Cancer Biology, Department of Biochemistry and Molecular Biology; \\ ${ }^{2}$ State Key Laboratory of Military Stomatology, Department of Oral and Maxillofacial Surgery, School of Stomatology; \\ ${ }^{3}$ The State Key Laboratory of Cancer Biology, Department of Pharmacogenomics, \\ School of Pharmacy, The Fourth Military Medical University, Xi'an, Shaanxi 710032; \\ ${ }^{4}$ Department of Clinical Laboratory, General Hospital of Xinjiang Military Command, Xinjiang 830000; \\ ${ }^{5}$ School of Basic Medical Sciences, Shaanxi University of Chinese Medicine, \\ Xianyang, Shaanxi 712046, P.R. China
}

Received June 16, 2018; Accepted October 24, 2018

DOI: $10.3892 /$ or.2018.6882

\begin{abstract}
Epithelial-mesenchymal transition (EMT) is required for the distant metastasis of tumors. The degree of tumor malignancy increases as EMT progresses. Notably, the biology of tumor cells differs from that of normal cells, with regards to characteristics and energy metabolism mechanisms; abnormal glucose metabolism, excessive accumulation of fatty acids and other metabolic disorders occur in metastatic tumors. Previous studies have confirmed that the regulation of tumor cell metabolism can affect tumor metastasis and some findings have resulted in novel clinical applications. The present review aimed to provide a basis for treatments targeting the tumor EMT process and metabolic reprogramming.
\end{abstract}

\section{Contents}

1. Introduction

2. The EMT process and cancer progression

3. Metabolism and EMT

Correspondence to: Dr Liangliang Shen, The State Key Laboratory of Cancer Biology, Department of Biochemistry and Molecular Biology, The Fourth Military Medical University, 169 Changle West Road, Xi'an, Shaanxi 710032, P.R. China

E-mail: bioliangshen@fmmu.edu.cn

Dr Xuan Qu, School of Basic Medical Sciences, Shaanxi University of Chinese Medicine, 1 Shiji Avenue, Xianyang, Shaanxi 712046, P.R. China

E-mail: quxuan519@163.com

${ }^{*}$ Contributed equally

Key words: tumor metabolic reprogramming,epithelial-mesenchymal transition
4. Glucose metabolism during EMT

5. Lipid metabolism during EMT

6. Amino acid metabolism during EMT

7. Nucleic acid metabolism during EMT

8. Enzymes and EMT

9. EMT and CSCs

10. Metabolism-associated oncogenes and tumor-suppressor genes

11. Conclusion and prospects

\section{Introduction}

Tumor metabolic reprogramming refers to the establishment of an entirely new metabolic network under the abnormal expression of oncogenes and tumor-suppressor genes, by which the flow of nutrients and energy in the metabolic network is redefined during the process of tumorigenesis. This reprogramming results in increased glucose uptake $(1,2)$, accumulation of lactate (3), enhanced nucleic acid synthesis (4), lipid metabolism disorders (5) and other alterations (6). Metabolism operates at a higher level in tumor cells than in normal cells, which is an adaptive process required to meet the needs of proliferation and migration. Cellular metabolism and transformation to metastatic disease serve important roles in tumor development (7-10).

Tumor metastasis is a unique feature of tumor cells that affects the survival and prognosis of patients with cancer; it is also an important reason why surgery cannot completely remove tumor lesions. The epithelial-mesenchymal transition (EMT) is an important process that occurs prior to tumor metastasis (11-14). During EMT, tumor cells change from an epithelioid morphology to mesenchymal cell morphology, with increases in cellular metabolism and decreases in adhesion between cells; the latter promotes migration (15-17). Previous studies regarding the molecular biology of tumor EMT have reported that gene mutations, deletions and translocations 
have an impact on various signaling pathways within cells, including the transforming growth factor (TGF)- $\beta(18,19)$, Wnt/ $\beta$-catenin $(20,21)$, Notch $(22)$, Hedgehog $(23,24)$ and interleukin-6/signal transducer and activator of transcription 3 (STAT3) signaling pathways $(25,26)$. The major carcinogenic signaling pathways ultimately influence tumor cell metabolism, and such metabolic alterations are essential for tumor occurrence and development (27). Metabolic reprogramming can provide both material for cell expansion and sustained signals for proliferation in order to meet the survival needs of tumor cells in specific microenvironments (28). The present study reviewed the metabolic reprogramming that occurs in EMT, in order to provide novel information that may improve cancer cure rates.

\section{The EMT process and cancer progression}

EMT.Epithelial cells have long been considered to be terminally differentiated cells that serve protective, supportive and secretory roles in animals. These cells have a typical apical-basal polarity. In addition, the presence of intercellular tight connections and adhesive connections allows epithelial cells to function together, while also limiting their ability to migrate freely. Previous studies have reported that the characteristics of cell polarity, and tight and adhesive connections, can be lost in epithelial cells $(11,29)$; cells in which these characteristics are lost are able to infiltrate and migrate, eventually adopting the morphology and characteristics of mesenchymal cells. This alteration is defined as the transition from epithelial cells to mesenchymal cells (i.e., EMT). An early-detected cytokine that induces EMT was initially named a 'scatter factor' and was later identified as hepatocyte growth factor (HGF); other cytokines that induce EMT include epidermal growth factor (EGF), fibroblast growth factor (FGF) and TGF- $\beta(30,31)$. Among these, the most common is TGF- $\beta$, and it has been confirmed that TGF- $\beta$ induces EMT in the majority of epithelial cells and epithelial-derived tumor cells in vivo and in vitro (18). Factors affecting the tumor internal environment, such as hypoxia, also induce EMT (32). The features of EMT are illustrated in Fig. 1.

E-cadherin reduction or loss. The reduction or loss of E-cadherin, a type I cadherin, is the most important landmark change associated with EMT. In cell adhesion, the extracellular domain of E-cadherin binds to that of E-cadherin molecules in adjacent cells, whereas the intracellular region forms a complex with $\alpha$-catenin, $\beta$-catenin and actin (33). In addition to mediating a strong physical connection between cells, E-cadherin is an important molecule that maintains epithelial cell identity. Cells that lose E-cadherin expression are characterized as non-epithelial cells and exhibit loss of polarity. Upon decreases in the levels of E-cadherin, intracellular $\beta$-catenin is released and translocates to the nucleus, where it forms a $\beta$-catenin/LEF complex that activates specific mesenchymal gene transcription. A relationship between E-cadherin and epithelial cancer has previously been reported (34). Furthermore, mutations in the E-cadherin gene, or downregulation of E-cadherin protein expression, are detected in lung, breast, gastric and prostate cancer, as well as other types of epithelial cancer (34). The E-cadherin gene is considered a novel tumor-suppressor gene, mutation and loss of which are key molecular events during cancer progression and metastasis (34).

Loss and relocalization of zonula occludens-1 (ZO-1). Tight junctions, which are located just below the apical surface of epithelial cells, have an important role in sealing gaps between cells. One of the molecules involved is ZO-1, which binds to the cytoskeleton and acts as a signaling molecule in the cell. Following EMT, downregulation of ZO-1 protein expression and interruption of tight junctions are observed (35). In addition, ZO-1 at the membrane can migrate to the cytoplasm and even the nucleus. Nuclear ZO-1 activates the EGF receptor, promotes the proliferation of cancer cells and augments the infiltration capacity of pancreatic tumor cells (35). The $\mathrm{N}$-terminal of the ZO-1 protein is critical for targeting cell borders, and $\mathrm{N}$-terminal mutants result in a marked alteration in cell shape and patterns of gene expression associated with the mesenchymal phenotype in corneal epithelial cells (36).

EMT and the extracellular matrix. A tumor is a complex cell cluster, the growth and infiltration of which are associated with the microenvironment formed by the extracellular matrix. A previous study reported that extracellular matrix components can promote the occurrence of EMT in tumor cells, and that cells undergoing EMT can alter the composition of the extracellular matrix to facilitate tumor infiltration and metastasis. For example, some tumor cells secrete matrix metalloproteinase (MMP)3 and MMP28 into the extracellular matrix, inducing EMT via Ras-related C3 botulinum toxin substrate 1 and reactive oxygen free radicals (37). In primary hepatocellular carcinoma, EMT can promote expression of MMP1, MMP2 and MMP7 in cells via upregulation of Snail and zinc finger E-box binding homeobox (ZEB2) transcription factors, thus resulting in the degradation of extracellular matrix proteins and enhancement of tumor cell infiltration (38).

Growth factor-induced EMT. EMT can be induced during tumor progression (39). Growth factor signaling pathways lead to loss of E-cadherin function through protein degradation and gene mutation. In several tumors, the tumor-associated stroma produces various growth factors and cytokines, including HGF, EGF, platelet-derived growth factor, FGF2, tumor necrosis factor (TNF) $\alpha$, insulin-like growth factor and TGF- $\beta$. TGF $\beta$-induced EMT is the most prominent type of EMT, which can be regulated by lipogenesis-related energy production (40). All of the aforementioned growth factors and cytokines may induce the expression of various E-cadherin transcription inhibitors, including Snail1/2, ZEB1/2 and Twist $(34,41)$, thus inhibiting the expression of E-cadherin, eventually resulting in EMT.

EMT also relies on the activation of various signaling pathways, including the mitogen-activated protein kinase (MAPK), phosphoinositide 3-kinase (PI3K), Wnt/ $\beta$-catenin, nuclear factor $(\mathrm{NF})-\kappa \mathrm{B}$, Notch and Hippo/Warts signaling pathways (34). For example, HGF stimulates EMT through activation of early growth response-1 via the MAPK signaling pathway, followed by Snail-1 expression and downregulation of E-cadherin gene expression (34). Similarly, FGF induces EMT via the activation of MAPK and TGF- $\beta$ signaling (34). In addition, Notch signaling can induce EMT through 


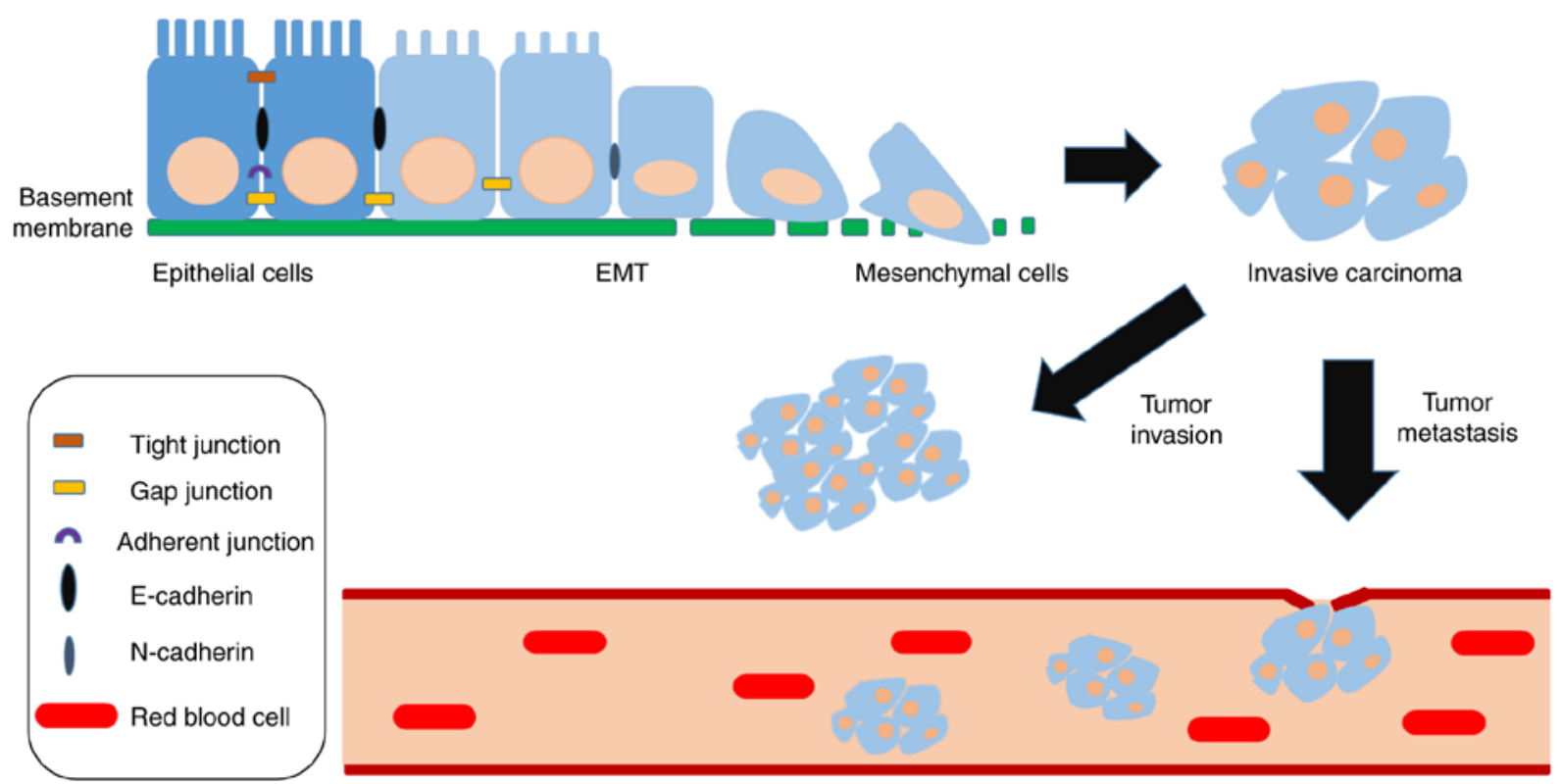

Figure 1. General characteristics of EMT. The transition of epithelial cells to a mesenchymal phenotype, induced by the tumor microenvironment or certain variations, is mainly manifested in the loss of cell polarity, as well as tight junctions and adherent junctions, thus resulting in the generation of mesenchymal cells from epithelial cells, and increased migratory and invasive capacities. The loss of E-cadherin induced by upregulated expression of mesenchymal markers (e.g., Snail1/2, Twist, zinc finger E-box binding homeobox 1/2) is the most important landmark change associated with EMT, which is often accompanied by enhanced $\mathrm{N}$-cadherin expression. Compared with E-cadherin, an increase in $\mathrm{N}$-cadherin is positively correlated with malignancy, infiltration and metastasis of cancer cells, and directly affects patient prognosis. EMT, epithelial-mesenchymal transition.

transcriptional activation of Snail-1 and Snail-2 through the cooperation with hypoxia $(22,42)$.

Transcription factor-induced EMT. Transcription factors have an important role in EMT induction, including Snail, Twist and ZEB (43). They can regulate the expression of certain genes, including E-cadherin, $\beta$-catenin, $\mathrm{N}$-cadherin, vimentin and fibronectin, to suppress substances associated with the tight linkage of cells. In addition, they are regulated by intracellular and extracellular signaling pathways to participate in EMT and promote tumor metastasis.

Snail was the first transcription factor reported to induce EMT. It can be combined with lysine-specific demethylase 1, G9a-DNA methyltransferase (DNMT), SUV39H1, mSin3A, histone deacetylase $1 / 2$ and other enzymes to methylate or acetylate the histone in the promoter region of E-cadherin, thereby inhibiting transcription of the target gene (44). In the human skin cancer cell line A431-III, RNA interference of Snail gene expression, significantly reduces the secretion of MMP9 and blocks the EMT, thus significantly reducing tumor invasion and metastasis; conversely, overexpression of Snail promotes vimentin and $\mathrm{N}$-cadherin expression, decreases E-cadherin and significantly increases the secretion of MMP9, thus promoting tumor invasion and metastasis (45). Haraguchi et al used ovarian cancer cells (RMZ-1), in which Snail was knocked out by CRISPR/Cas9 technology, to further clarify the effects of Snail on the maintenance of cytoskeletal structure, cell migration and cell-cell adhesion (46). Kim et al reported that Snail can reprogram glucose metabolism by suppressing phosphofructokinase, platelet, a major isoform of cancer-specific phosphofructokinase-1, an enzyme involved in the first rate-limiting step of glycolysis, thus allowing cancer cell survival under metabolic stress (47).
Twist is a member of the basic helix-loop-helix transcription factor family, which includes Twist1 and Twist2. Twist is also a key regulatory factor involved in EMT and metastasis. Breast cancer cell lines and tumor animal models have confirmed that Twist1 can induce EMT and promote tumor invasion and metastasis; Twistl acts on the promoter H4K20me1 of E-cadherin and N-cadherin genes to inhibit E-cadherin gene transcription and enhance $\mathrm{N}$-cadherin gene transcription through the recruitment of SET8 (48). When normal breast epithelial cells and breast cancer cell lines express Twist2, it can activate the STAT3 signaling pathway to reduce E-cadherin, resulting in cells obtaining the mesenchymal cell phenotype and promotion of tumor metastasis. Meanwhile, normal breast epithelial cells and breast cancer cells obtain a tumor stem cell-like phenotype through the activation of Twist2 (49).

Overexpression of ZEB protein is closely associated with tumorigenesis and metastasis. At present, it has been reported that overexpression of ZEB exists in ovarian, breast, lung, prostate, colon and bladder cancer (50). ZEB can induce EMT in tumor cells via the induction of MMPs (50). Gene chips have been used to detect gene expression in 38 patients with non-small cell lung cancer; the results revealed that ZEB1 and ZEB2 can regulate the expression of $>400$ genes, most of which are closely associated with tumor EMT, including epithelial cellular adhesion molecule, CDP-diacylglycerol synthase 1 , suppression of tumorigenicity 14 , FGF receptor 1 and vimentin (51).

\section{Metabolism and EMT}

Metabolic phenotypes of cancer cells. In early tumor stages, the metabolic phenotypes of tumor cells are similar to normal 
cells $(1,2)$. With the development of EMT, differentiated epithelial cancer cells are replaced with undifferentiated mesenchymal cancer cells; the metabolic phenotypes of these cells are also altered (52). To date, the key characteristics of cell metabolism in mesenchymal cells have been fully addressed.

Increased glycolytic flux. Aerobic glycolysis is increased in mesenchymal cancer cells to minimize reactive oxygen species (ROS) (53), which are the main source of cellular metabolic damage partially produced by oxidative phosphorylation. Aerobic glycolysis better satisfies the basic needs of dividing cells: Rapid ATP production, increased macromolecular biosynthesis and enhanced maintenance of appropriate cellular redox status (54). During EMT, glycolysis is more active in cancer cells, which not only satisfies the basic needs of cancer cells for appropriate energy levels, adequate biosynthetic precursors and balanced redox status, but also helps maintain a poorly differentiated state (55).

Rapid ATP generation from glycolysis. Glucose metabolism provides ATP to cells through mitochondrial oxidative phosphorylation and glycolysis. However, since the ATP provided by oxidative phosphorylation in mesenchymal cancer cells usually does not meet the proliferation requirements, cells tend to use glycolysis, a pathway with low glucose utilization but rapid delivery of ATP, to obtain energy $(56,57)$.

Increased pentose phosphate pathway (PPP) flux. Alterations in the PPP are directly associated with the growth state of cells. The microenvironment of undifferentiated mesenchymal cancer cells serves a key role in the metabolic phenotype of cancer cells. Hypoxia and lactic acid accumulation promote cancer cells to increase the flow of PPP, providing a material basis for the rapid growth of cancer cells (58). Two aspects determine the redox equilibrium state of cells: The production and elimination rate of ROS. It has been reported that ROS links glucose metabolism to the EMT phenotype in basal-like breast cancer. and that the EMT phenotype promotes metabolic conversion to glucose metabolism, leading to decreased ROS levels (59-61). The loss of fructose-bisphosphatase 1, a rate-limiting metabolic enzyme of gluconeogenesis, can inhibit oxygen consumption and ROS production by suppressing the activity of mitochondrial complex I and increasing the synthesis of NADPH through PPP flux, which subsequently increases the mesenchymal phenotype in breast cancer (55).

Activated Thr-Gly metabolism. Threonine and glycine can synthesize S-adenosyl methionine (SAM), which is a common substrate for DNA and histone methylation in cells, by folate metabolism (62). DNMTs and histone methyltransferases (HMTs) can transfer methyl groups from SAM to substrates, in order to form the by-product S-adenosyl homocysteine (SAH), which is an effective inhibitor of DNMT and HMTs, thereby adding methyl groups to DNA or lysine/arginine residue of histones (63). In mesenchymal cells, Thr-Gly metabolism is activated, and threonine dehydrogenase promotes SAM synthesis while converting threonine to glycine and acetyl-CoA, resulting in a high ratio of SAM/SAH. SAM and SAH hydrolase can both activate enhancer of zeste 2 polycomb repressive complex 2 subunit, a methyltransferase involved in suppressing gene expression through methylation of histone $\mathrm{H} 3$ on lysine 27, resulting in H3K27me3-dependent inactivation of E-cadherin (64).

\section{Glucose metabolism during EMT}

Glucose metabolism. Compared with normal cells, tumor cells exhibit a stronger ability to absorb glucose; however, the capacity to use this substance is weak, even under conditions of sufficient oxygen. As tumor cells primarily invoke glycolysis to obtain energy, which is accompanied by lactic acid accumulation and a small amount of ATP, an anoxic environment is generated. This process is called the Warburg effect $(56,57)$; compared with primary tumors, the Warburg effect is more prominent in metastatic tumors.

Mitochondrial dysfunction. Mitochondria are the main organelles that supply energy in human cells, and are also involved in the transmission of apoptotic signals in normal cells. These functions of mitochondria determine their close association with numerous diseases, including cancer. It has been reported that mitochondrial dysfunction is significantly associated with glucose metabolic reprogramming and the ability to lose autonomic apoptosis in several types of metastatic cancer (65). The structure and function of mitochondria in cancer cells is altered, alongside mitochondrial expansion, increased glucose intake and lactate accumulation, during EMT, whereas the glucose oxidation capacity of mitochondria declines (66). In breast cancer and melanoma cells, the reduced glucose oxidation in mitochondria can enhance the EMT process to accelerate tumor metastasis (67). Pathological alterations in mitochondrial membrane permeability can release some apoptotic proteins; however, the numerous anti-apoptotic signals, including B-cell lymphoma 2 (Bcl-2) and Bcl-extra large, in tumor cells inhibit these apoptotic proteins. It has been reported that the Bcl-2 family member Mcl-1 is expressed during tumor metastasis, and its anti-apoptotic ability is required for tumor metastasis (68). With regards to mitochondrial function in tumor-associated changes, maintaining normal mitochondrial signaling, enhancing mitochondrial oxidative capacity, and regulating the expression of apoptotic proteins are potential directions for clinical research.

Lactic acid accumulation. Glucose metabolism provides ATP to cells through mitochondrial oxidative phosphorylation and glycolysis; however, since the supply of ATP due to mitochondrial oxidative phosphorylation does not typically meet the proliferation requirements of tumor cells, tumors tend to employ glycolysis to obtain energy (69,70). A direct result is an increase in the lactate content of tumor cells; notably, the levels of lactic acid in tumor cells are directly associated with the EMT process and metastatic behavior of tumors (71). Accumulation of lactic acid can induce expression and activation of enzymes associated with glycolysis, including hexokinase and 6-phosphofructokinase 1, to enhance the supply of ATP in tumor cells. Tumor cells can use lactic acid as a source of energy for metabolism and also procure lactic acid from surrounding cells to maintain the acidic environment, in order to avoid apoptosis and promote metastasis (72). Glucose metabolism in endothelial cells produces lactic 
acid, which can promote angiogenesis and provide a suitable environment for metastasis. Liu et al revealed that EMT induction is associated with augmented glucose uptake and lactate production in pancreatic ductal adenocarcinoma (73). Exogenous lactic acid can also favor metastasis of cancer cells in a concentration-dependent manner in head and neck carcinoma cells (74), and these advantages enable EMT, tumor invasion and metastasis. Furthermore, previous studies have reported that the lactic acid accumulated in tumor cells functions through the TGF- $\beta 2$ signaling pathway to induce tumor cell metastasis $(70,74)$, and experiments in mice have demonstrated that cell metastasis is blocked when the glycolytic pathway is inhibited (75). These findings indicate that a reduction in lactic acid alters the acidic environment of tumor cells, eliminates the advantages of the tumor cell microenvironment, and reduces available energy sources for tumor cell metabolism; this may be a potential strategy to prevent tumor cell metastasis.

Pyruvate. During glycolysis, phosphoenolpyruvate, the intermediate that is converted to pyruvate by pyruvate kinase, is key. It has been reported that normal cells mainly express pyruvate kinase muscle (PKM)1, whereas tumor cells aberrantly express PKM2 (76). In addition, it has been demonstrated that c-Myc gene-mediated selective cleavage is the main reason for tumor-specific expression of PKM2 (77), which is mainly present in the form of a dimer. PKM2 promotes the biosynthesis of glycolytic intermediates. In addition, PKM2 dimers participate in signal transduction in the form of active phosphokinase and are involved in the regulation of gene transcription together with $\beta$-catenin $(78,79)$, hypoxia-inducible factor (HIF) and other transcription factors following nuclear translocation (80). The nuclear translocation of PKM2 induced by stroma impairs oxidative phosphorylation and metastatic spread in prostate cancer (81). Abnormal expression of PKM2 is positively correlated with EMT in esophageal squamous cell, gallbladder and papillary thyroid cancers (82-84), and interference of PKM2 expression significantly inhibits tumor growth, invasion and metastasis (85).

$H I F$. Tumor cells grow rapidly in the body, and rapid proliferation, vascular remodeling and a lack of blood supply, generally mean that these cells are maintained in an anoxic state. A hypoxic microenvironment can enhance the resistance of tumor cells to chemotherapy, reducing the survival rate of patients. This state can also activate HIF-1 $\alpha$, which is associated with tumor metabolism and metastasis-associated gene activation (86-88). A previous study reported that HIF-1 may promote EMT and metastasis (89). Song et al reported that HIF-1 $\alpha$ can increase the gene expression levels of pyruvate kinase-2, phosphokinase-1, glucose transporter (GLUT)1 and lactate dehydrogenase A (LDHA) expression under hypoxic conditions, promoting carbohydrate metabolism in cells, and providing energy to promote tumor growth and metastasis during EMT (90). In addition, instantaneous activation of HIF-1 $\alpha$ can induce LDHA expression and E1 subunit phosphorylation of pyruvate dehydrogenase, resulting in the transition from intracellular glucose metabolic pathways and mitochondrial oxidative phosphorylation to anaerobic glycolysis and lactate fermentation (91). When this transition is inhibited by an HIF-1 $\alpha$ inhibitor, 3-(5'-hydroxymethyl-2'-furan)-1-benzylindazole, the levels of ROS produced during chemotherapy are increased, and the formation of metastatic lung tumors is inhibited $(92,93)$. Therefore, reducing HIF-1 $\alpha$ expression in tumor cells and decreasing the enhancement of glycolysis by HIF- $\alpha$ in tumor cells may reduce their energy intake, inhibit EMT and reduce metastasis.

HIF- $1 \alpha$ can activate TGF- $\beta /$ Smad 3 and Wnt signaling pathways, upregulate the expression levels of TWIST and Snail, and promote the invasion and metastasis of tumor cells through EMT induction. It has previously been reported that the expression levels of HIF-1 $\alpha$ and EMT-associated transcription factors are positively associated in tumor cells (64). HIF-1 $\alpha$ can directly or indirectly induce EMT-associated gene expression, thus promoting EMT in breast cancer (52). Previous studies have revealed that HIF-1 $\alpha$ regulates $>40$ factors, including Snail, ZEB2, TWIST, Slug, carbonic anhydrase IX, etc., through various signaling pathways to support tumor metastasis $(78,79)$.

Glucose metabolism and drug resistance. In the majority of cancers, drug resistance is the leading cause of chemotherapy failure. It has been reported that cellular metabolic disorders are associated with this resistance. Ippolito et al revealed that docetaxel-resistant PC3 (PC3-DR) cells undergo EMT and possess strong metastatic properties (94). Furthermore, PC3-DR cells have a more efficient metabolic phenotype than other cells, involving the use of glucose, glutamine and lactic acid by mitochondrial oxidative phosphorylation; therefore, compromising this metabolic reprogramming may be a successful treatment strategy.

\section{Lipid metabolism during EMT}

Fatty acid metabolism and EMT. Fatty acids are essential constituents of biofilm lipids and signaling molecules, and are important substrates for energy metabolism $(95,96)$. When cultured in the same medium, lipids in adipocytes can be redirected to ovarian cancer cells to provide energy for expansion of cancer cells (97). However, tumor cells do not ingest exogenous fatty acids in vivo but rather consume a large amount of ATP and NADPH (to synthesize one fatty acid molecule, 14 molecules of ATP and seven molecules of NADPH are required), a process termed fatty acid de novo synthesis. The fatty acids required for malignant tumor growth and proliferation are mainly derived from the de novo synthesis pathway, and fatty acid de novo synthesis is a unique characteristic of malignant cancer (5). Menendez et al suggested that tumor cells are always self-synthesizing fatty acids to maintain rapid proliferation and achieve survival (98). In addition, the fatty acid synthesis pathway protects cells from oxygen free radicals and chemotherapeutic agents by consuming reduced equivalents of NAPDH to balance cell oxidation-reduction levels. These conditions provide the energy and environment for tumor EMT and ultimately promote tumor metastasis.

Fatty acid synthase (FASN) and EMT. FASN, the only key enzyme in fatty acid de novo synthesis, is expressed in tumors, such as breast cancer and melanoma (99). Due to the increased levels of FASN expression, $>90 \%$ of triglycerides 
are synthesized de novo, despite the presence of high levels of free fatty acids in cells. Tumor cells are highly dependent on the de novo synthesis of fatty acids, such that inhibition of fatty acid synthesis through FASN will selectively induce apoptosis in human cancer cells, but has little effect on normal cells (100). FASN serves a crucial role in tumor EMT and regulates the process in two ways: i) FASN induces the composition and stability of lipid rafts, which in turn affect proteins located in the rafts to promote phosphorylation of E-cadherin and lead to its degradation, weakening intercellular contact and inducing EMT (101-103); ii) FASN induces the occurrence and progression of EMT by altering the palmitoylation level of Wnt and activating the Wnt/ $\beta$-catenin signaling pathway (102). Inhibition of FASN can reverse EMT in breast cancer and colorectal cancer cells, thus inhibiting tumor cell invasion, metastasis and drug resistance $(102,103)$; therefore, the study of FASN inhibitors may provide a novel means for tumor treatment and prognosis.

Cholesterol and EMT. Cholesterol is a key component of the cell membrane, particularly the cytoplasmic membrane (104), and is a precursor of such compounds as steroid hormones, bile acids and vitamins (105). Previous studies have revealed that cholesterol metabolism is closely associated with tumor EMT $(106,107)$. For example, Alikhani et al demonstrated that, in a breast cancer animal model, abnormal levels of plasma cholesterol promote EMT and accelerate tumor cell metastasis (108). Furthermore, it has been reported that the use of statins to inhibit cholesterol synthesis can suppress cancer invasion and metastasis (109-112). The specific molecular mechanism by which cholesterol metabolism affects tumor EMT is not yet clear; however, there are numerous hypotheses that may be involved.

Firstly, a lipid raft is a microstructure in the plasma membrane that is rich in cholesterol and sphingolipid, and serves an important role in biological processes, including signal transduction and cytoplasmic membrane protein sorting (113). As a key component of lipid rafts, alterations in cholesterol levels can affect the structure and function of lipid rafts (114). Lipid rafts are closely associated with signal transduction in EMT through such factors as osteopontin (OPN), which is an important tumor-promoting molecule. OPN activates MAPK, PI3K/AKT serine/threonine kinase (AKT) and $N F-\kappa B$, through its receptor protein $\alpha v \beta 3$ integrin and cluster of differentiation (CD)44, which are located on lipid rafts $(115,116)$, in order to enhance the expression of MMP2, MMP9, urinary plasminogen activator and other genes, thus promoting tumor EMT (117). Furthermore, reducing cholesterol levels in the plasma membrane to destroy lipid raft structure can cause removal of CD44 from the membrane, thus inhibiting EMT in tumor cells (118). In addition, lipid rafts have an important role in activation of the EGF receptor (EGFR) signaling pathway, which is an important signaling pathway in tumor invasion and metastasis (119). It has been reported that breast cancer cell lines exhibit resistance to EGFR tyrosine kinase inhibitors when EGFR is located in lipid rafts, but using methyl $\beta$-cyclodextrin or statins to reduce cholesterol and destroy lipid rafts can counteract this effect (120).

Secondly, farnesyl pyrophosphate (FPP) and geranylgeranyl pyrophosphate (GGPP) are two important metabolites in the bypass route of cholesterol metabolism. These two metabolites are involved in the prenylation of Ras and Rho proteins; prenylation is necessary for the binding and activation between Ras and Rho and the cell membrane (112). A previous study regarding glioma reported that inhibition of cholesterol synthesis leads to a decrease in FPP and GGPP metabolites, thus inhibiting the Ras-Raf-MAPK kinase-extracellular signal-regulated kinase (ERK) signaling pathway and leading to a decrease in the growth and invasion of glioma cells (121).

Finally, research on breast cancer has revealed that abnormal cholesterol metabolism causes accumulation of its metabolite 27-hydroxycholesterol, which promotes breast cancer growth and EMT by activating estrogen receptor (ER) and liver X receptor $(122,123)$.

\section{Amino acid metabolism during EMT}

Amino acids in tumor cells. Tumor cells not only require the necessary energy reserves to maintain their survival, but also a large amount of biological raw materials that are used to generate new sub-cells. Previous studies have reported the significance of abnormal metabolism of glutamate, aspartic acid, glycine and serine, as well as other amino acids, during tumor growth, invasion and metastasis $(70,124,125)$. The present review described the mechanisms by which these amino acids are metabolically broken down during tumor metastasis.

Glutamine and EMT. Roberts and Frankel, and Roberts and Borges reported that some tumor types predominantly use glutamine for survival $(126,127)$. These tumor cells do not necessarily rely on glucose uptake but rather on glutamine-dependent growth, a phenomenon called 'glutamine addiction' $(128,129)$. Glutamine predominantly produces $\alpha$-ketoglutarate $(\alpha-K G)$ in the mitochondria and provides the raw material for oxidative phosphorylation and lipid synthesis through the tricarboxylic acid cycle (TCA) cycle (70). In addition, glutaminase (GLS) and glutamate dehydrogenase 1 (GDH1), which are the key enzymes of glutamine metabolism, are highly expressed in lymphoma and prostate cancer cells and are closely associated with the classification and prognosis of a tumor via regulation of the oncogene c-Myc (130). Reducing expression of GLS or GDH1 can inhibit lipid synthesis or induce intracellular redox stress, thus resulting in apoptosis of tumor cells $(131,132)$. Furthermore, oxidative stress during tumor progression is an important factor for inhibiting the distant metastasis of melanoma cells (133). Conversely, fumarate, which is the intermediate metabolite of glutamine metabolism, can reduce the levels of ROS in breast cancer cells by activating glutathione peroxidase, thus maintaining the redox balance $(95,132)$, which may promote the EMT process and metastasis.

Additionally, in the human body, different types of cells use distinct metabolic pathways due to their phenotypic differences. In breast cancer, basal-like cancer cells with the mesenchymal phenotype are more sensitive to glutamine-targeted therapy than luminal cells with an epithelial phenotype, possibly due to different patterns of glutamine metabolism (134). However, the specific mechanism underlying abnormal amino acid metabolism in tumors remains to be elucidated. 


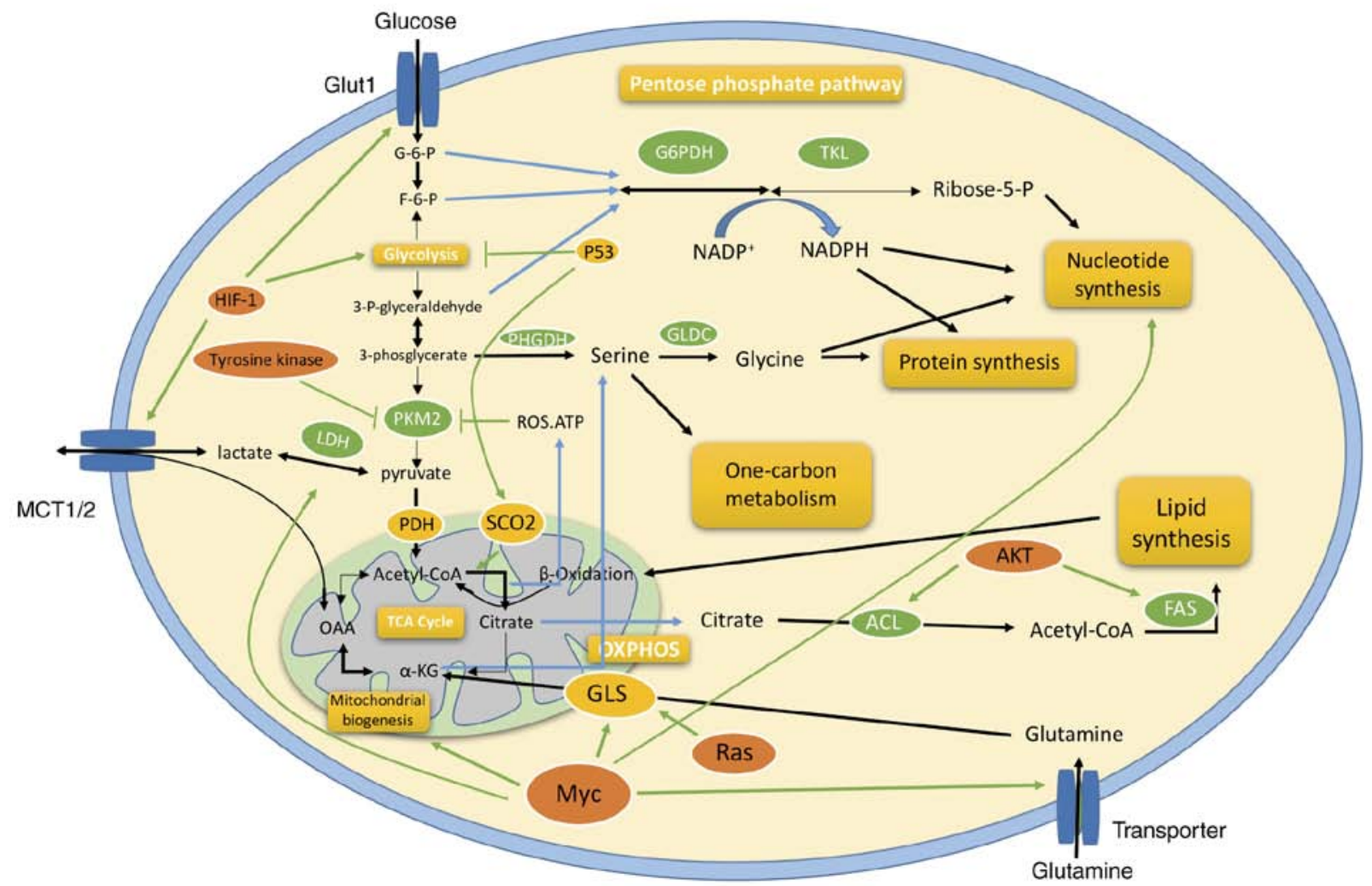

Figure 2. Schematic diagram of the metabolic reprogramming of cancer cells during EMT. Various aspects of metabolic reprogramming during EMT are shown, including glycolysis, the TCA cycle, pentose phosphate pathway, glutaminolysis, and biosynthesis of fatty acid, nucleotide and amino acid pathways. The key molecules, including c-Myc, p53, HIF-1 $\alpha$, RAS and AKT, coordinate regulation of cancer metabolism in different ways. ACL, ATP-citrate lyase; $\alpha$-KG, $\alpha$-ketoglutarate; AKT, AKT serine/threonine kinase; F6P, fructose-6-phosphate; FAS, fatty acid synthase; G6P, glucose-6-phosphate; G6PDH, glucose-6-phosphate dehydrogenase; GLDC, glycine decarboxylase; GLS, glutaminase; Glut1, glucose transporter 1; HIF, hypoxia-inducible factor; LDH, lactate dehydrogenase; MCT, monocarboxylate transporter, OXPHOS, oxidative phosphorylation; PDH, pyruvate dehydrogenase; PFK, phosphofructokinase; PHGDH, phosphoglycerate dehydrogenase; PKM2, pyruvate kinase muscle 2; SCO2, synthesis of cytochrome $c$ oxidase 2; TCA, tricarboxylic acid.

Glycine and EMT. Glycine has an important role as a provider of carbon units. Analysis of the in vivo metabolic pathway in patients with glioma revealed that glucose ingested by tumor cells can be used as a carbon source for de novo synthesis of glycine (135) (Fig. 2). This experiment revealed that glycine de novo synthesis has a very important role in the progression of human tumors. In addition, metabolic analysis of NCI-60 tumor cell lines indicated that the rapid proliferation of tumor cells is increasingly dependent on glycine, and that the proliferation rate of tumor cells has a close association with glycine consumption and the expression levels of molecules that are important for mitochondrial glycine synthesis (136). High levels of glycine synthesis are a prerequisite for tumor EMT and also contribute to tumor metastasis in lung cancer (136). Glycine is also a building block for protein synthesis, and isotope labeling revealed that glycine is utilized in the synthesis of purines, which are key raw materials for nucleic acid synthesis, and proteins (Fig. 2) (137). Expression of glycine decarboxylase (GLDC), which is a rate-limiting enzyme of the glycine cleavage system, is abnormally high in tumor-initiating cells of non-small cell lung cancer (138). GLDC functions in a manner similar to that of oncogenes, and overexpression of GLDC alters metabolism of glycine, glycolysis and synthesis of pyrimidines, which are also an important component of nucleotides (Fig. 2). In addition, glycine is a glycogenic amino acid and can be converted by serine transhydroxymethylase to serine, from which pyruvate is then generated (139). Therefore, glycine metabolism is an important pathway for serine biosynthesis. Conversely, it has also been reported that the addition of glycine to food inhibits proliferation of melanoma B16 cells in mice (140); the mechanism underlying these effects is considered to occur via food-borne glycine inhibition of vascular endothelial cell proliferation, thus leading to disordered angiogenesis.

Serine and EMT. Although serine is a non-essential amino acid, it has an indispensable role in metabolism. Serine is involved in the biosynthesis of S-adenosylmethionine and is the most important carbon unit in the methylation reaction (141). Phosphoglycerate dehydrogenase (PHGDH) catalyzes the first step of serine synthesis and can also control the flow of glycolytic intermediates into the serine biosynthetic pathway (142) (Fig. 2). The PHGDH gene is located in the region of recurrent copy number gain in breast cancer, and expression of the PHGDH protein is upregulated in $70 \%$ of ER-negative breast cancer tissues (142). The serine synthesis flux in breast cancer cells with high PHGDH protein expression is increased, and inhibition of PHGDH expression in cells with high $\mathrm{PHGDH}$ protein expression can reduce serine synthesis and decrease the ability of cells to proliferate. Serine is a glucogenic amino acid that can be converted to pyruvate, $\alpha-K G$ and other TCA cycle intermediates, in order 
to participate in gluconeogenesis, thus generating glucose. However, a decrease in PHGDH does not result in a decrease in intracellular serine concentration but induces a decrease in $\alpha-K G$, which can be converted to glutamine by glutamine synthase via the mitochondrial TCA cycle (142). It has previously been reported that $\sim 50 \%$ of the glutamine flow entering the TCA cycle is from the serine synthesis pathway in cells with high PHGDH protein expression (142). Serine can also be decomposed into acetyl-CoA, which is a main participant in the TCA cycle, and can enter TCA cycle oxidation; acetyl-CoA can be further converted to fatty acids by FAS. Therefore, it is reasonable to speculate that the synthesis of serine in tumor cells can be used for fatty acid synthesis. Abnormal expression of serine and its related enzymes in tumor cells is likely to be an important factor in the metabolic reprogramming of tumor cells, as well as a source of energy for tumor development. Inhibition or reversal of these abnormal alterations may provide novel ideas for inhibiting tumor progression, including the development of EMT.

\section{Nucleic acid metabolism during EMT}

Nucleic acids are among the most basic molecules, which serve a decisive role in such processes as growth, inheritance and variation. Cells in different organisms have particular characteristics; in addition, the metabolism of tumor cells and normal cells in the human body differs significantly, and the various levels of development of tumor cells also differ widely. It has been reported that thymidylate kinase and thymidine kinase are key for de novo synthesis and salvage synthesis of pyrimidine nucleotides, and are more active in tumor cells than in normal cells (4). This phenomenon is more pronounced during tumor metastasis. With the development of molecular imaging technology, alterations in cell morphology can be observed and detection of nucleic acid synthesis during tumor cell metastasis can be conducted (143). During metastasis, the rapid proliferation of cells includes the transmission of genetic information, transcription, translation and other process, inevitably leading to increased synthesis of DNA and RNA. Although food contains a sufficient amount of nucleic acids, only a small portion of their decomposition products can be used for re-synthesis of nucleic acids. Notably, a large portion of the raw material required for nucleic acid synthesis is derived from carbohydrate metabolism; for example, ribose 5-phosphate produced via degradation of glucose 6-phosphate in the PPP can be catalyzed to pyrophosphate 5-phosphate with ATP, via a specific ribose-phosphate pyrophosphokinase, for mononucleotide synthesis. Therefore, carbohydrate metabolism is considered the material basis of nucleic acid synthesis during tumor metastasis (58). With the development of molecular biology, the purpose of which is to identify mechanisms, the focus of research on tumor metastasis is largely conducted at the genetic level; for example, microRNA (miR)-10b promotes cell metastasis and the mesenchymal subtype of glioblastoma multiforme via the suppression of tumor protein p53 (TP53), paired box 6, NOTCH1 and homeobox D10 (144); long non-coding RNA HOX transcript antisense RNA induces genome-wide re-targeting of polycomb repressive complex 2 to an occupancy pattern more resembling embryonic fibroblasts, leading to altered histone H3 lysine 27 methylation, gene expression, and increased cancer invasiveness and metastasis (145). Conversely, little attention has been given to the metabolism of macromolecules. In tumor metastasis research, inhibition or activation of certain enzymes at the level of nucleic acid synthesis may reveal a novel target for tumor therapy.

\section{Enzymes and EMT}

In the process of EMT during tumor metastasis, enzyme catalysis is highly relevant for nucleic acid, carbohydrate and lipid metabolism. As an example, glucose-6-phosphate dehydrogenase, which is a key enzyme in the PPP, is capable of continuously synthesizing nucleotides and lipids to meet the material and energy requirements of tumor metastasis. Therefore, glucose-6-phosphate dehydrogenase is considered a potential antitumor target (146). Oxygenated glycosylated proteins can enhance glycosyltransferase activity and are therefore a major marker of migration in ovarian cancer cells. Because glycosylation of polypeptide N-acetylgalactosyltr ansferase 14 (GALNT14) is associated with transmembrane mucin-13, and both are found at high levels in ovarian cancer cells, suppression of the GALNT14 gene by small interfering RNA may inhibit cell metastasis, indicating that GALNT14 can promote tumor metastasis by modulating transmembrane mucin-13 (147). It has been reported that heparanase serves an important role in tumor invasion and metastasis, and tumor cell invasion and metastasis are inhibited by the heparanase inhibitor OGT2115, as well as low-molecular-weight heparin (148). The reduced form of NADPH oxidase is the main source of ROS, and ROS can induce apoptosis of endothelial cells in vivo, which is a prerequisite for tumor cells to escape from the circulatory system and migrate to other tissues and organs (149). It has been reported that angiotensin-converting enzyme-2, which is a key enzyme in the kidney-angiotensin system, can attenuate the metastasis of non-small cell lung cancer through inhibition of EMT (150). Furthermore, AMP-activated protein kinase (AMPK) induces cell transfer, although its function remains unclear; knockout of the AMPK gene in an ovarian cancer xenograft model can significantly inhibit tumor metastasis to the lungs, whereas AMPK activation induced by lysophosphatidic acid promotes ovarian cancer cell metastasis (151). However, AMPK- $\alpha 2$ protects against liver injury from metastasized tumors via reduced glucose deprivation-induced oxidative stress, including alleviating hepatic hypoglycemia and mitochondria-mediated inhibition of ROS production (152).

These results indicate that different enzymes serve important roles in the process of tumor metastasis through distinct pathways. By studying the regulation of enzymes during tumor cell metastasis, the synthesis rate of nucleotides and lipids can be specifically reduced, as can the energy utilization of tumor cells. The use of inhibitors to inhibit the activity of metastasis-associated enzymes is one of the most commonly applied clinical treatments.

\section{EMT and CSCs}

Cancer stem cells (CSCs) are a small population of cells within tumor tissues, which possess the capacities of self-renewal, multipotent differentiation, unlimited proliferation and strong 
tumorigenic ability (153). They maintain tumor growth and proliferation. The insensitivity of tumors to radiotherapy and chemotherapy, tumor recurrence and metastasis are all closely associated with CSCs. To date, scientists have isolated CSCs in various solid tumors, such as liver, breast, lung, and brain stem tumors (154-157).

By comparing the main metabolic patterns of metastatic prostate epithelial CSCs (e-CSCs) with non-CSCs expressing stable EMT. Aguilar et al revealed that e-CSCs possess a high degree of plasticity with regards to energy metabolism, including enhanced glycolysis, fat and amino acid metabolism, and glutamine metabolism (158), which indicates that metabolic reprogramming of cancer cells predominantly occurs in CSCs. Correct identification of key metabolic participants that are regulated post-transcriptionally can provide potential biomarkers and therapeutic targets for the effective prevention of metastasis (158).

EMT is a key developmental program that is often activated during cancer invasion and metastasis. It has been reported that EMT can transform immortalized human mammary epithelial cells into cells with CSC properties, thus indicating that EMT-transformed cells have stem cell properties, and inducing EMT can not only promote the proliferation of tumor cells from the primary site, but also enhance the self-renewal ability of tumor cells (159). Therefore, EMT can transform tumor cells into CSCs, and CSCs may acquire an increased migratory ability through EMT transformation (160).

The majority of poorly differentiated cancers usually evade cancer treatment; however, the reason is unclear. Oshimori et al indicated that TGF- $\beta$, which is concentrated in the tumor vasculature, confers a longer cell renewal cycle of adjacent squamous cell carcinoma stem cells (SCC-SC). $\mathrm{SCC}-\mathrm{SC}$, in response to TGF- $\beta$, exhibits enhanced protection against anticancer drugs; however, a longer cell renewal cycle alone will not improve survival. In addition, TGF- $\beta$ activates p21 and stabilizes nuclear factor (erythroid-derived 2)-like 2, thereby significantly enhancing glutathione metabolism and therapeutic resistance (161). Furthermore, activated TGF- $\beta$ can bind to the high-affinity receptors T $\beta R I$ and T $\beta R I I$, which have serine/threonine protein kinase activity, on the tumor cell membrane to activate Smad2 and Smad3 (19). Smad2 and Smad3 enter into the nucleus alongside Smad4 to interact with other transcription factors, inducing the expression of target genes, such as Snail1, Snail2 and ZEB, eventually leading to reduction of E-cadherin and induction of $\mathrm{N}$-cadherin and vimentin, thus resulting in increased motility of tumor cells (19). TGF- $\beta$ can also induce EMT through non-Smad pathways by activating ERK MAPK, Rho GTPases, PI3K/AKT and other signaling pathways (19).

It has been reported that under hypoxic conditions, CSCs are more prone to EMT, leading to cell morphological alterations and enhanced metastatic capacity. However, EMT can be reduced when the normoxic control level is restored, indicating that this is a reversible process. Notably, due to the action of cytokines such as TNF $\alpha$, even under normoxic conditions, there is still a small portion of CSCs that undergo EMT (162). These differences in oxygen metabolism patterns provide an explanation for the general therapeutic resistance of CSCs and the greater resistance of CSCs that develop EMT.
Biddle et al reported that non-EMT and EMT CSCs can switch their epithelial or mesenchymal traits to reconstitute cellular heterogeneity; this is a characteristic of CSCs (163). CSCs can switch between epithelial and mesenchymal cells via EMT and mesenchymal-epithelial transition. Previous studies revealed that post-EMT CSCs exhibit particularly enhanced therapeutic resistance $(163,164)$. In conclusion, selecting an appropriate targeted therapy based on the different phenotypes of CSCs is key to effective outcomes.

\section{Metabolism-associated oncogenesand tumor-suppressor genes}

Association of oncogenes and tumor-suppressor genes with metabolism. Rapid proliferation of cells requires a sufficient amount of new biological macromolecules for cellular construction. These biological macromolecules vary widely, and may be obtained directly from the extracellular environment or by metabolism of glucose, which is a common nutrient for the synthesis of other required biological macromolecules. Therefore, the maximum utilization of available nutrients and conversion into other molecules through complex metabolic networks is the most important goal of tumor cell metabolism. Previously, researchers believed that a tumor is the result of oncogene activation or tumor-suppressor gene inactivation, and that metabolic abnormalities were merely concomitant phenomena of the genetic events that induce tumors (28). However, the results of cell metabolism studies in recent decades have revealed that genetic events, including oncogene activation and tumor-suppressor gene inactivation, thus affecting genes such as Kras, p53, c-myc and isocitrate dehydrogenase (IDH), may be initiators of malignant cell transformation, with metabolic reprogramming being an essential pathway underlying the genetic events that mediate malignant transformation, including EMT, to promote tumor metastasis (165-168). Notably, increasing evidence has suggested that several classical oncogenes or tumor-suppressor genes are directly or indirectly involved in metabolic reprogramming (169-171). As aforementioned, tumor metabolism reprogramming may have an important role in promoting EMT.

Kras. Carcinogenic mutations of the Kras gene are an early event in pancreatic cancer. The proliferation of mouse pancreatic cancer driven by the mutant Kras gene $\mathrm{Kras}(\mathrm{G} 12 \mathrm{D})$, is highly dependent on $\mathrm{Kras}(\mathrm{G} 12 \mathrm{D})$ expression, resulting in reprogrammed cellular metabolism to support proliferation (165). Kras(G12D) can stimulate tumor cells to take up glucose and drive glucose intermediate metabolites into the hexose amine biosynthesis and the PPP pathways to promote ribose synthesis. Unlike the classical model, Kras(G12D) drives glycolysis intermediates into the non-oxidized PPP, resulting in loss of contact between ribose synthesis and NADP/NADPH-mediated redox control (165). Kras metabolizes glucose and glutamine to support cell growth and promotes growth capacity that is not dependent on docking (172). This effect is achieved by regulating the ERK/MAPK signaling pathway to induce ROS production and glutamine entry into the TCA cycle to be metabolized to $\alpha-K G$ (173) (Fig. 2). In addition, H-ras 
$(\mathrm{G} 12 \mathrm{~V})$ or K-ras $(\mathrm{G} 12 \mathrm{~V})$ can increase the number of functional mitochondria in cells and maintain mitochondrial metabolism by increasing autophagy to promote tumor cell survival (174).

p53. As a well-known tumor-suppressor gene, $\mathrm{p} 53$ is also the most important negative regulator during tumor metabolic reprogramming, which has been reported to regulate EMT and metastasis in colorectal cancer (166). In addition, p53 inhibits glycolysis, promotes fatty acid oxidation and is associated with the maintenance of an appropriate redox status (58). p53 can inhibit expression of GLUT1, GLUT4 and phosphoglycerate mutase to upregulate expression of TP5-induced glycolysis regulatory phosphatase, thereby suppressing glycolysis (175-177). In addition, p53 can promote expression of synthesis of cytochrome $c$ oxidase 2 (SCO2), which is critical for regulating the cytochrome $c$ oxidase (COX) complex (169) (Fig. 2). Decreased p53 expression in cancer cells results in decreased $\mathrm{SCO} 2$ protein expression and reduced oxygen consumption, which provides a possible explanation for the Warburg effect, and offers novel information as to how p53 may affect tumor growth and metastasis. Furthermore, in serous ovarian cancer cells, a mutated p53 gene can enhance lipid metabolism to promote tumor cell metastasis, accompanied by epithelial cell transformation to mesenchymal cells, fatty acid uptake promotion in adipocytes and invasive alterations in other tumor cells, eventually leading to decreased patient survival (178).

$c-M y c$. The well-known tumorigenic transcription factor c-Myc can induce EMT and metabolic reprogramming through numerous routes. It can stimulate glycolysis, glutaminolysis and nucleotide synthesis $(135,170)$; induce EMT in mammary epithelial cells; cooperate with TGF- $\beta$ in promoting EMT and metastasis (179); and promote EMT and angiogenesis through upregulating miR9 (167). c-Myc-dependent tumor cells appear to be 'glutamine-addicted'. c-Myc can also promote the use of glutamate in tumor cell mitochondria by activating the enzymes involved in glutamine metabolism, an effect known as glutaminolysis (134). In addition to directly regulating expression of metabolic enzymes, c-Myc stimulates the conversion of glutamine to glutamate in tumor cells, and its entry into the TCA cycle. This results in generation of ATP to support proliferation via inhibition of miR-23a/b transcription and upregulation of GLS1 expression (180) (Fig. 2), which has been confirmed to serve a key role in the induction of Snail-dependent EMT and promotion of tumor metastasis (181). c-Myc can also promote glycolysis via direct induction of the expression of glycolytic-associated enzymes, including hexokinase 2 and phosphoinositide-dependent protein kinase-1 (182), which promotes stemness and EMT phenotypes in cancer cells (183). c-Myc-mediated metabolic reprogramming is largely achieved by effects on mitochondria. The mutual interplay between mitochondrial metabolism and EMT has been fully addressed (184). Recently, ${ }^{13} \mathrm{C}$-labeled metabolite tracer detection revealed that c-Myc-driven lymphoma cells are highly dependent on mitochondrial aerobic metabolism (185). In addition, c-Myc can promote mitochondrial biogenesis and maintain the number and function of mitochondria in tumor cells (Fig. 2).
$I D H$. IDH is responsible for catalyzing the metabolism of isocitrate into $\alpha$-KG. IDH in mitochondria employs $\mathrm{NAD}^{+}$ as a coenzyme, whereas IDH in the cytoplasm uses $\mathrm{NADP}^{+}$ as a coenzyme, although both catalyze the same reaction. A high frequency of mutations in IDH1 and IDH2 occurs in glioma (186). Furthermore, IDH mutations are found in patients with acute myeloid leukemia and myelodysplastic syndrome (187). A high frequency of IDH mutation sites associated with tumors are located at the active site of IDH1 or IDH2, and mutation hotspots include the IDH1 gene R132 locus and IDH2 gene R172 locus. Mutations in both sites reduce the ability of IDH to catalyze the conversion of isocitrate to $\alpha-K G$, whereas the ability to reduce $\alpha-K G$ is enhanced, generating 2-hydroxyglutarate (2HG), which is considered a potential carcinogenic metabolite $(171,188)$. Because mutations in IDH almost always occur on one allele, with the other remaining wild type, a single IDH allele mutation does not seriously affect the ability of IDH to convert isocitrate to $\alpha-\mathrm{KG}$. The most serious consequences are caused by the accumulation of $2 \mathrm{HG}$, a by-product of the TCA cycle, which is present in normal cells at a very low level. The mechanism by which mutated IDH leads to tumor occurrence has various explanations. It has been reported that mutation of IDH1 in astrocytes is sufficient to cause hypermethylation of the genome, which is commonly found in glioma and other tumors (189). A previous study regarding leukemia also revealed that IDH mutations can lead to an increase in $2 \mathrm{HG}$ production as a result of TET2 inactivation, causing genome hypermethylation (190). However, another study demonstrated that AGH-5198, which specifically inhibits mutations at the R132H site, can suppress the growth of glioma cells without causing significant alterations in genomic methylation levels (191). This finding suggests that IDH mutation not only leads to genomic epigenetic alterations but possibly additional mechanisms to promote tumorigenesis. In addition, IDH1 mutations lead to EMT through upregulation of the transcription factor ZEB1 and downregulation of the miR-200 family of miRs (192). Furthermore, the oncometabolite $2 \mathrm{HG}$ can directly induce EMT and distant metastasis in colorectal cancer (168).

\section{Conclusion and prospects}

Metabolic reprogramming is an essential pathway for genetic events that mediate malignant transformation, including EMT, thus promoting tumor metastasis. Aberrant expression of genes including Kras, p53, c-Myc and IDH induces metabolic reprogramming. Through subversive metabolic adjustment, tumor cells are provided access to the required energy supply, and balancing the energy supply and synthesis of biological macromolecules is important to achieve rapid proliferation of cell populations. Inducing EMT not only promotes the proliferation of tumor cells from the primary site, but also enhances the self-renewal ability of tumor cells. EMT can transform tumor cells into CSCs, and CSCs may acquire migratory ability through EMT transformation, in order to help tumor cells escape drug treatment. This review summarized the interactions between tumor metabolic reprogramming and EMT in tumor cells, aiming to provide insights into targeting key metabolic molecules for the treatment of tumor metastasis. 


\section{Acknowledgements}

Not applicable.

\section{Funding}

The present study was financially sponsored by grants from the National Natural Science Foundation of China (grant nos. 31401161, 81502370 and 81702845), the State Key Laboratory of Cancer Biology Project (grant no. CBSKL2017Z11) and the Special Program of Shaanxi Educational Commission (grant no. 17JK0220).

\section{Availability of data and materials}

All data generated or analyzed during this study are included in this published article.

\section{Authors' contributions}

$\mathrm{ML}, \mathrm{XB}, \mathrm{BC}, \mathrm{XQ}$ and LS performed the literature search and wrote the paper. PL and KL performed the literature search. XQ and LS approved the final version of the manuscript to be published.

\section{Ethics approval and consent to participate}

Not applicable.

\section{Patient consent for publication}

Not applicable.

\section{Competing interests}

The authors declare that they have no competing interests.

\section{References}

1. Kroemer G and Pouyssegur J: Tumor cell metabolism: Cancer's Achilles' heel. Cancer Cell 13: 472-482, 2008.

2. Mayevsky A: Mitochondrial function and energy metabolism in cancer cells: Past overview and future perspectives Mitochondrion 9: 165-179, 2009.

3. Walenta S and Mueller-Klieser WF: Lactate: Mirror and motor of tumor malignancy. Semin Radiat Oncol 14: 267-274, 2004.

4. Sakamoto S, Tsukada K, Sagara T, Kawachi Y, Murakami S and Iwama T: Human colorectal malignancy and oral UFT. Anticancer Res 22: 339-341, 2002.

5. Santos CR and Schulze A: Lipid metabolism in cancer. FEBS J 279: 2610-2623, 2012.

6. Furuta E, Okuda H, Kobayashi A and Watabe K: Metabolic genes in cancer: Their roles in tumor progression and clinical implications. Biochim Biophys Acta 1805: 141-152, 2010.

7. Martin RM, Vatten L, Gunnell D, Romundstad P and Nilsen TI: Components of the metabolic syndrome and risk of prostate cancer: The HUNT 2 cohort, Norway. Cancer Causes Control 20 : $1181-1192,2009$

8. Siegel AB and Zhu AX: Metabolic syndrome and hepatocellular carcinoma: Two growing epidemics with a potential link. Cancer 115: 5651-5661, 2009.

9. Stocks T, Lukanova A, Johansson M, Rinaldi S, Palmqvist R, Hallmans G, Kaaks R and Stattin P: Components of the metabolic syndrome and colorectal cancer risk; A prospective study. Int J Obes 32: 304-314, 2008
10. Kabat GC, Kim M, Chlebowski RT, Khandekar J, Ko MG, McTiernan A, Neuhouser ML, Parker DR, Shikany JM, Stefanick ML, et al: A longitudinal study of the metabolic syndrome and risk of postmenopausal breast cancer. Cancer Epidemiol Biomarkers Prev 18: 2046-2053, 2009.

11. Hugo H, Ackland ML, Blick T, Lawrence MG, Clements JA, Williams ED and Thompson EW: Epithelial-mesenchymal and mesenchymal-epithelial transitions in carcinoma progression. J Cell Physiol 213: 374-383, 2007.

12. Foroni C, Broggini M, Generali D and Damia G: Epithelialmesenchymal transition and breast cancer: Role, molecular mechanisms and clinical impact. Cancer Treat Rev 38: 689-697, 2012.

13. Thiery JP: Epithelial-mesenchymal transition in development and pathologies. Curr Opin Cell Biol 15: 740-746, 2003.

14. Yilmaz M and Christofori G: EMT, the cytoskeleton, and cancer cell invasion. Cancer Metastasis Rev 28: 15-33, 2009.

15. Christofori $\mathrm{G}$ and Semb H: The role of the cell-adhesion molecule E-cadherin a tumour-suppresor gene. Trends Biochemci Sci 24: 73-76, 1999.

16. Hiery JP: Epithelial-mesenchymal transitions in tumour progression. Nat Rev Cancer 2: 442-454, 2002.

17. Boyer B, Valls AM and Edme N: Induction and regulation of epithelial-mesenchymal transitions. Biochem Pharmacol 60: 1091-1099, 2000.

18. Saitoh M and Miyazawa K: Transcriptional and post-transcriptional regulation in TGF- $\beta$-mediated epithelial-mesenchymal transition. J Biochem 151: 563-71, 2012.

19. Xu J, Lamouille S and Derynck R: TGF-beta-induced epithelial to mesenchymal transition. Cell Res 19: 156-172, 2009.

20. Gradl D, Kuhl M and Wedlich D: The Wnt/Wg signal transducer beta-catenin controls fibronectin expression. Mol Cell Biol 19: 5576-5587, 1999.

21. Gilles C, Polette M, Mestdagt M, Nawrocki-Raby B, Ruggeri P, Birembaut $\mathrm{P}$ and Foidart JM: Transactivation of vimentin by beta-catenin in human breast cancer cells. Cancer Res 63: 2658-2664, 2003.

22. Wang Z, Li Y, Kong D and Sarkar FH: The role of Notch signaling pathway in epithelial-mesenchymal transition (EMT) during development and tumor aggressiveness. Curr Drug Targets 11: 745-751, 2010.

23. Kume T: The role of FoxC2 transcription factor in tumor angiogenesis. J Oncol 2012: 204593, 2012.

24. Harris TJ and Tepass U: Adherens junctions: From molecules to morphogenesis. Nat Rev Mol Cell Biol 11: 502-514, 2010.

25. Sullivan NJ, Sasser AK, Axel AE, Vesuna F, Raman V, Ramirez N, Oberyszyn TM and Hall BM: Interleukin-6 induces an epithelial-mesenchymal transition phenotype in human breast cancer cells. Oncogene 28: 2940-2947, 2009.

26. Cheng GZ, Zhang WZ, Sun M, Wang Q, Coppola D, Mansour M, $\mathrm{Xu}$ LM, Costanzo C, Cheng JQ and Wang LH: Twist is transcriptionally induced by activation of STAT3 and mediates STAT3 oncogenic function. J Biol Chem 283: 14665-14673, 2008.

27. Cairns R, Harris IS and Mak TW: Regulation of cancer cell metabolism. Nat Rev Cancer 11: 85-95, 2011.

28. Hanahan D and Weinberg R: Hallmarks of cancer: The next generation. Cell 144: 646-674, 2011.

29. Christiansen JJ and Rajasekaran AK: Reassessing epithelial to mesenchymal transition as a prerequisite for carcinoma invasion and metastasis. Cancer Res 66: 8319-8326, 2006.

30. Kaartinen V, Voncken JW, Shuler C, Warburton D, Bu D, Heisterkamp N and Groffen J: Abnormal lung development and cleft palate in mice lacking TGF-beta-3 indicates defects of epithelial-mesenchymal interaction. Nat Genet 11: 415-421, 1995.

31. Khoury H, Dankort DL, Sadekova S, Naujokas MA, Muller WJ and Park M: Distinct tyrosine autophosphorylation sites mediate induction of epithelial mesenchymal like transition by an activated ErbB-2/Neu receptor. Oncogene 20: 788-799, 2001.

32. Lester RD, Jo M, Montel V, Takimoto S and Gonias SL: UPAR induces epithelial-mesenchymal transition in hypoxic breast cancer cells. J Cell Biol 178: 425-436, 2007.

33. Gheldof A and Berx G: Cadherins and epithelial-to-mesenchymal transition. Prog Mol Biol Transl Sci 116: 317-336, 2013.

34. Tiwari N, Gheldof A, Tatari M and Christofori G: EMT as the ultimate survival mechanism of cancer cells. Semin Cancer Biol 22: 194-207, 2012. 
35. Takai E, Tan X, Tamori Y, Hirota M, Egami H and Ogawa M: Correlation of translocation of tight junction protein Zonula occludens-1 and activation of epidermal growth factor receptor in the regulation of invasion of pancreatic cancer cells. Int J Oncol 27: 645-651, 2005.

36. Ryeom SW, Paul D and Goodenough DA: Truncation mutants of the tight junction protein $\mathrm{ZO}-1$ disrupt corneal epithelial cell morphology. Mol Biol Cell 11: 1687-1697, 2000.

37. Radisky DC, Levy DD, Littlepage LE, Liu H, Nelson CM, Fata JE, Leake D, Godden EL, Albertson DG, Nieto MA, et al: Raclb and reactive oxygen species mediate MMP-3-induced EMT and genomic instability. Nature 436: 123-127, 2005.

38. Miyoshi A, Kitajima Y, Sumi K, Sato K, Hagiwara A, Koga Y and Miyazaki K: Snail and SIP1 increase cancer invasion by upregulating MMP family in hepatocellular carcinoma cells. Br J Cancer 90: 1265-1273, 2004.

39. Thiery JP, Acloque H, Huang RY and Nieto MA: Epithelialmesenchymal transitions in development and disease. Cell 139: 871-890, 2009.

40. Jiang L, Sugiura H, Sugiura H, Huang X, Ali A, Kuro-o M, Deberardinis RJ and Boothman DA: Metabolic reprogramming during TGF $\beta 1$-induced epithelial-to-mesenchymal transition. Oncogene 34: 3908-3916, 2015.

41. Zhang H, Liu CY, Zha ZY, Zhao B, Yao J, Zhao S, Xiong Y, Lei QY and Guan KL: TEAD transcription factors mediate the function of TAZ in cell growth and epithelial-mesenchymal transition. J Biol Chem 284: 13355-13362, 2009.

42. Sahlgren C, Gustafsson MV, Jin S, Poellinger L and Lendahl U: Notch signaling mediates hypoxia-induced tumor cell migration and invasion. Proc Natl Acad Sci USA 105: 6392-6397, 2008.

43. Zheng $\mathrm{H}$ and Kang Y: Multilayer control of the EMT master regulators. Oncogene 33: 1755-1763, 2014.

44. Wang Y, Shi J, Chai K, Ying X and Zhou BP: The role of snail in EMT and tumorigenesis. Curr Cancer Drug Targets 13: 963-972, 2013.

45. Lin CY, Tsai PH, Kandaswami CC, Lee PP, Huang CJ, Hwang JJ and Lee MT: Matrix metalloproteinase- 9 cooperates with transcription factor Snail to induce epithelial-mesenchymal transition. Cancer Sci 102: 815-827, 2011.

46. Haraguchi M, Sato M and Ozawa M: CRISPR/Cas9n-mediated deletion of the snail lgene (SNAII) reveals its role in regulating cell morphology, cell-cell interactions, and gene expression in ovarian cancer (RMG-1) cells. PLoS One 10: e0132260, 2015.

47. Kim NH, Cha YH, Lee J, Lee SH, Yang JH, Yun JS, Cho ES, Zhang X, Nam M, et al: Snail reprograms glucose metabolism by repressing phosphofructokinase PFKP allowing cancer cell survival under metabolic stress. Nat Commun 8: 14374, 2017.

48. Yang F, Sun L, Li Q, Han X, Lei L, Zhang H and Shang Y: SET8 promotes epithelial-mesenchymal transition and confers TWIST dual transcriptional activities. EMBO J 31: 110-123, 2012.

49. Fang X, Cai Y, Liu J, Wang Z, Wu Q, Zhang Z, Yang CJ, Yuan L and Ouyang G: Twist 2 contributes to breast cancer progression by promoting an epithelial-mesenchymal transition and cancer stem-like cell self-renewal. Oncogene 30: 4707-4720, 2011.

50. Tania M, Khan MA and Fu J: Epithelial to mesenchymal transition inducing transcription factors and metastatic cancer. Tumour Biol 35: 7335-7342, 2014.

51. Gemmill RM, Roche J, Potiron VA, Nasarre P, Mitas M, Coldren CD, Helfrich BA, Garrett-Mayer E, Bunn PA and Drabkin HA: ZEB1-responsive genes in non-small cell lung cancer. Cancer Lett 300: 66-78, 2011.

52. Halldorsson S, Rohatgi N, Magnusdottir M, Choudhary KS, Gudjonsson T, Knutsen E, Barkovskaya A, Hilmarsdottir B, Perander M, Mælandsmo GM, et al: Metabolic re-wiring of isogenic breast epithelial cell lines following epithelial to mesenchymal transition. Cancer Lett 396: 117-129, 2017.

53. Anastasiou D, Poulogiannis G, Asara JM, Boxer MB, Jiang JK, Shen M, Bellinger G, Sasaki AT, Locasale JW, Auld DS, et al: Inhibition of pyruvate kinase M2 by reactive oxygen species contributes to cellular antioxidant responses. Science 334 : 1278-1283, 2011

54. Cairns RA, Harris IS and Mak TW: Regulation of cancer cell metabolism. Nat Rev Cancer 11: 85-95, 2011.

55. Dong C, Yuan T, Wu Y, Wang Y, Fan TW, Miriyala S, Lin Y, Yao J, Shi J, Kang T, et al: Loss of FBP1 by Snail-mediated repression provides metabolic advantages in Basal-like breast cancer. Cancer Cell 23: 316-331, 2013.
56. Warburg O, Posener K and Negelein E: Ueber den stoffwechsel der tumoren. Biochemische Zeitschrif 152: 319-344, 1924 (In German).

57. Porporato PE, Payen VL, Perez-Escuredo J, De Saedeleer CJ, Danhier P, Copetti T, Dhup S, Tardy M, Vazeille T, Bouzin C, et al: A mitochondrial switch promotes tumor metastasis. Cell Rep 8: 754-766, 2014.

58. Wood T: Physiological functions of the pentose phosphate pathway. Cell Biochem Funct 4: 241-247, 1986.

59. Schieber MS and Chandel NS: ROS links glucose metabolism to breast cancer stem cell and EMT phenotype. Cancer Cell 23: 265-267, 2013.

60. Liu HW, Zhu X, Zhang J, Zhang XB and Tan W: A red emitting two-photon fluorescent probe for dynamic imaging of redox balance meditated by a superoxide anion and GSH in living cells and tissues. Analyst 141: 5893-5899, 2016.

61. Diehn M, Cho RW, Lobo NA, Kalisky T, Dorie MJ, Kulp AN, Qian D, Lam JS, Ailles LE, Wong M, et al: Association of reactive oxygen species levels and radioresistance in cancer stem cells. Nature 458: 780-783, 2009.

62. Locasale JW: Serine, glycine and one-carbon units: Cancer metabolism in full circle. Nat Rev Cancer 13: 572-583, 2013.

63. Luka Z, Mudd SH and Wagner C: Glycine $N$-methyltransferase and regulation of $S$-adenosylmethionine levels. J Biol Chem 284: 22507-22511, 2009.

64. McCabe MT, Ott HM, Ganji G, Korenchuk S, Thompson C, Van Aller GS, Liu Y, Graves AP, Della Pietra A III, Diaz E, et al: EZH2 inhibition as a therapeutic strategy for lymphoma with EZH2-activating mutations. Nature 492: 108-112, 2012.

65. Cook CC, Kim A, Terao S, Gotoh A and Higuchi M: Consumption of oxygen: A mitochondrial generated progression signal of advanced cancer. Cell Death Dis 3: e258, 2012.

66. Chiche J, Rouleau M, Gounon P, Brahimi-Horn MC, Pouysségur J and Mazure NM: Hypoxic enlarged mitochondria protect cancer cells from apoptotic stimuli. J Cell Physiol 222: 648-657, 2010.

67. Kamarajugadda S, Stemboroski L, Cai Q, Simpson NE, Nayak S, Tan M and Lu J: Glucose oxidation modulates anoikis and tumor metastasis. Mol Cell Biol 32: 1893-1907, 2012.

68. Andersen JL and Kornbluth S: Mcl-1 rescues a glitch in the matrix. Nat Cell Biol 14: 563-565, 2012.

69. VanderHeidenMG,Cantley LCand ThompsonCB: Understanding the Warburg effect: The metabolic requirements of cell proliferation. Science 324: 1029-1033, 2009.

70. Morandi A, Taddei ML, Chiarugi P and Giannoni E: Targeting the metabolic reprogramming that controls epithelial-to-mesenchymal transition in aggressive tumors. Front Oncol 7: 40, 2017.

71. Bonuccelli G, Tsirigos A, Whitaker-Menezes D, Pavlides S, Pestell RG, Chiavarina B, Frank PG, Flomenberg N, Howell A, Martinez-Outschoorn UE, et al: Ketones and lactate 'fuel' tumor growth and metastasis: Evidence that epithelial cancer cells use oxidative mitochondrial metabolism. Cell Cycle 9: 3506-3514, 2010.

72. Doherty JR and Cleveland JL: Targeting lactate metabolism for cancer therapeutics. J Clin Invest 123: 3685-3692, 2013.

73. Liu M, Quek LE, Sultani G and Turner N: Epithelial-mesenchymal transition induction is associated with augmented glucose uptake and lactate production in pancreatic ductal adenocarcinoma. Cancer Metab 4: 19, 2016.

74. Goetze K, Walenta S, Ksiazkiewicz M, Kunz-Schughart LA and Mueller-Klieser W: Lactate enhances motility of tumor cells and inhibits monocyte migration and cytokine release. Int J Oncol 39: 453-463, 2011.

75. Sotnik JL, Lori JC, Rose BJ and Thamm DH: Glycolysis inhibition by 2-deoxy-D-glucose reverts the metastatic phenotype in vitro and in vivo. Clin Exp Metastasis 28: 865-875, 2011.

76. Christofk HR, Vander Heiden MG, Harris MH, Ramanathan A, Gerszten RE, Wei R, Fleming MD, Schreiber SL and Cantley LC: The M2 splice isoform of pyruvate kinase is important for cancer metabolism and tumour growth. Nature 452: 230-233, 2008.

77. David CJ, Chen M, Assanah M, Canoll P and Manley JL: HnRNP proteins controlled by c-Myc deregulate pyruvate kinase mRNA splicing in cancer. Nature 463: 364-368, 2010.

78. Christofk HR, Vander HM, Wu N, Asara JM and Cantley LC: Pyruvate kinase M2 is a phosphotyrosine-binding protein. Nature 452: 181-186, 2008.

79. Hittosugi T, Kang S, Vander Heiden MG, Chung TW, Elf S, Lythgoe K, Dong S, Lonial S, Wang X, Chen GZ, et al: Tyrosine phosphorylation inhibits PKM2 to promote the Warburg effect and tumor growth. Sci Signal 2: ra73, 2009. 
80. Luo W, Hu H, Chang R, Zhong J, Knabel M, O'Meally R, Cole RN, Pandey A and Semenza GL: Pyruvate kinase M2 is a PHD3-stimulated coactivator for hypoxia-inducible factor 1 . Cell 145: 232-744, 2011

81. Elisa G, Maria LT, Andrea M, Comito G, Calvani M, Bianchini F, Richichi B, Raugei G, Wong N, Tang D and Chiarugi P: Targeting stromal-induced pyruvate kinase M2 nuclear translocation impairs oxphos and prostate cancer metastatic spread. Oncotarget 6: 24061-24074, 2015.

82. Zhan C, Shi Y, Lu C and Wang Q: Pyruvate kinase M2 is highly correlated with the differentiation and the prognosis of esophageal squamous cell cancer. Dis Esophagus 26: 746-753, 2013.

83. Li J, Yang Z, Zou Q, Yuan Y, Li J, Liang L, Zeng G and Chen S: PKM2 and ACVR 1C are prognostic markers for poor prognosis of gallbladder cancer. Clin Transl Oncol 16: 200-207, 2014

84. Feng C, Gao Y, Wang C, Yu X, Zhang W, Guan H, Shan Z and Teng W: Aberrant overexpression of pyruvate kinase M2 is associated with aggressive tumor features and the $B R A F$ mutation in papillary thyroid cancer. J Clin Endocrinol Metab 98 E1524-E1533, 2013.

85. Goldberg MS and Sharp PA: Pyruvate kinase M2-specific siRNA induces apoptosis and tumor regression. J Exp Med 209: 217-224, 2012

86. Yoo YG, Christensen J, Gu J and Huang LE: HIF-1 $\alpha$ mediates tumor hypoxia to confer a perpetual mesenchymal phenotype for malignant progression. Sci Signal 4: pt4, 2011.

87. Düvel K, Yecies JL, Menon S, Raman P, Lipovsky AI, Souza AL Triantafellow E, Ma Q, Gorski R, Cleaver S, et al: Activation of a metabolic gene regulatory network down stream of $m$ TOR complex 1. Mol Cell 39: 171-183, 2010.

88. Icard P, Kafara P, Steyaert JM, Schwartz L and Lincet H: The metabolic cooperation between cells in solid cancer tumors. Biochim Biophys Acta 1846: 216-225, 2014.

89. Wu CY, Tsai YP, Wu MZ, Teng SC and Wu KJ: Epigenetic reprogramming and post-transcriptional regulation during the epithelial-mesenchymal transition. Trends Genet 28: 454-463, 2012.

90. Song IS, Wang AG, Yoon SY, Kim JM, Kim JH, Lee DS and Kim NS: Regulation of glucose metabolism-related genes and VEGF by HIF-1alpha and HIF-1beta, but not HIF-2alpha, in gastric cancer. Exp Mol Med 41: 51-58, 2009.

91. Zhao T, Zhu Y, Morinibu A, Kobayashi M, Shinomiya K, Itasaka S, Yoshimura M, Guo G, Hiraoka M and Harada H HIF-1-mediated metabolic reprogramming reduces ROS levels and facilitates the metastatic colonization of cancers in lungs. Sci Rep 4: 3793, 2014.

92.Psaila B and Lyden D: The metastatic niche: Adapting the foreign soil. Nat Rev Cancer 9: 285-293, 2009.

93. Erler JT, Bennewith KL, Cox TR, Lang G, Bird D, Koong A, Le QT and Giaccia AJ: Hypoxia-induced lysyl oxidase is a critical mediator of bone marrow cell recruitment to form the premetastatic niche. Cancer Cell 15: 35-44, 2009.

94. Ippolito L, Marini A, Cavallini L, Morandi A, Pietrovito L, Pintus G, Giannoni E, Schrader T, Puhr M, Chiarugi P and Taddei ML: Metabolic shift toward oxidative phosphorylation in docetaxel resistant prostate cancer cells. Oncotarget 7 : 61890-61904, 2016

95. Mashek DG and Coleman RA: Cellular fatty acid uptake: The contribution of metabolism. Curr Opin Lipidol 17: 274-278, 2006.

96.Zechner R, Strauss JG, Haemmerle G, Lass A and Zimmermann R: Lipolysis: Pathway under construction. Curr Opin Lipidol 16: 333-340, 2005.

97. Nieman KM, Kenny HA, Penicka CV, Ladanyi A Buell-Gutbrod R, Zillhardt MR, Romero IL, Carey MS, Mills GB, Hotamisligil GS, et al: Adipocytes promote ovarian cancer metastasis and provide energy for rapid tumor growth Nat Med 17: 1498-1503, 2011.

98. Menendez JA, Vellon L, Oza BP and Lupu R: Does endogenous fatty acid metabolism allow cancer cells to sense hypoxia and mediate hypoxic vasodilatation? Characterization of a nove molecular connection between fatty acid synthase (FAS) and hypoxia-inducible factor-1alpha (HIF-1alpha)-related expression of vascular endothelial growth factor (VEGF) in cancer cells overexpressing her-2/neu oncogene. J Cell Biochem 94 857-863, 2005.

99. Swierczyński J and Sledziński T: Metabolic and regulatory function of fatty acid synthase. Postepy Biochem 58: 175-185, 2012 (In Polish).
100. Jeong NY, Lee JS, Yoo KS, Oh S, Choe E, Lee HJ, Park BS, Choi YH and Yoo YH: Fatty acid synthase inhibitor cerulenin inhibits topoisomerase I catalytic activity and augments SN-38-induced apoptosis. Apoptosis 18: 226-237, 2013.

101. Fujita Y, Krause G, Scheffner M, Zechner D, Leddy HE, Behrens J, Sommer T and Birchmeier W: Hakai, a c-Cbl-like protein, ubiquitinates and induces endocytosis of the E-cadherin complex. Nat Cell Biol 4: 222-231, 2002.

102. Li J, Dong L, Wei D, Wang X, Zhang S and Li H: Fatty acid synthase mediates the epithelial-mesenchymal transition of breast cancer cells. Int J Biol Sci 10: 171-180, 2014.

103. Rakheja D, Kapur P, Hoang MP, Roy LC and Bennett MJ: Increased ratio of saturated to unsaturated $\mathrm{C} 18$ fatty acids in colonic adenocarcinoma: Implications for cryotherapy and lipid raft function. Med Hypotheses 65: 1120-1123, 2005.

104. Ikonnen E: Roles of lipid rafts in membrane transport. Curr Oppin Cell Biol 13: 470-477, 2001.

105. Russell DW: The enzymes, regulation, and genetics of bile acid synthesis. Annu Rev Biochem 72: 137-174, 2003.

106. Pelton K, Freeman MR and Solomon KR: Cholesterol and cancer. Curr Opin Pharmacol 12: 751-759, 2012.

107. Kitahara CM, Berrington de González A, Freeman ND, Huxley R, Mok Y, Jee SH and Samet JM: Total cholesterol and cancer risk in a large prospective study in Korea. J Clin Oncol 29: 1592-1598, 2011

108. Alikhani N, Ferguson RD, Novosyadlyy R, Gallagher EJ, Scheinman EJ, Yakar S and LeRoith D: Mammary tumor growth and pulmonary metastasis are enhanced in a hyperlipidemic mouse model. Oncogene 32: 961-967, 2013.

109. Nielsen SF, Nordestgaard BG and Bojesen SE: Statin use and reduced cancer-related mortality. N Engl J Med 367: 1792-1802, 2012.

110. Taras D, Blanc JF, Rullier A, Dugot-Senant N, Laurendeau I, Vidaud $M$ and Rosenbaum J: Pravastatin reduces lung metastasis of rat hepatocellular carcinoma via a coordinated decrease of MMP expression and activity. J Hepatol 46: 69-76, 2007.

111. Zhang J, Yang Z, Xie L, Xu L, Xu D and Liu X: Statins, autophagy and cancer metastasis. Int J Biochem Cell BIol 45: 745-752, 2013.

112. Roy M, Kung HJ and Ghosh PM: Statins and prostate cancer: Role of cholesterol inhibition vs. prevention of small GTP-binding proteins. Am J Cancer Res 1: 542-561, 2011.

113. Simons K and Ikonen E: Functional rafts in cell membranes. Nature 387: 569-572, 1997.

114. Freeman MR, Di Vizio D and Solomon KR: The Rafts of the Medusa: Cholesterol targeting in cancer therapy. Oncogene 29: 3745-3747, 2010

115. Patra SK: Dissecting lipid raft facilitated cell signaling pathways incancer. Biochim Biophys Acta 1785: 182-206, 2008.

116. Mural T: The role of lipid rafts in cancer cell adhesion and migration. Int J Cell Biol 2012: 763283, 2012.

117. Rangaswami H, Bulbule A and Kundu GC: Osteopontin: Role in cell signaling and cancer progression. Trends Cell Biol 16 79-87, 2006.

118. Murai T, Maruyama Y, Mio K, Nishiyama H, Suga M and Sato C Low cholesterol triggers membrane microdomain-dependent CD44 shedding and suppresses tumor cell migration. J Biol Chem 286: 1999-2007, 2011.

119. Nicholson RI, Gee JM and Harper ME: EGFR and cancer prognosis. Eur J Cancer 37 (Suppl 4): S9-S15, 2001.

120. Irwin ME, Mueller KL, Bohin N, Ge Y and Boerner JL: Lipid raft localization of EGFR alters the response of cancer cells to the EGFR tyrosine kinase inhibitor gefitinib. J Cell Physiol 226: 2316-2328, 2011.

121. Afshordel S, Kern B, Clasohm J, König H, Priester M, Weissenberger J, Kögel D and Eckert GP: Lovastatin and perillyl alcohol inhibit glioma cell invasion, migration, and proliferation - impact of Ras-/Rho-prenylation. Pharmacol Res 91: 69-77, 2015.

122. Nelson ER, Wardell SE, Jasper JS, Park S, Suchindran S, Howe MK, Carver NJ, Pillai RV, Sullivan PM, Sondhi V, et al: 27-Hydroxycholesterol links hypercholesterolemia and breast cancer pathophysiology. Science 342: 1094-1098, 2013.

123. Wu Q, Ishikawa T, Sirianni R, Tang H, McDonald JG, Yuhanna IS, Thompson B, Girard L, Mineo C, Brekken RA, et al: 27-Hydroxycholesterol promotes cell-autonomous, ER-positive breast cancer growth. Cell Rep 5: 637-645, 2013.

124. Hensley CT, Wasti AT and Deberardinis RJ: Glutamine and cancer: Cell biology, physiology and clinical opportunities. J Clin Invest 123: 3678-3684, 2013. 
125. Kim D, Fiske BP,Birsoy K,FreinkmanE,KamiK,Possemato RL, Chudnovsky Y, Pacold ME, Chen WW, Cantor JR, et al: SHMT2 drives glioma cell survival in ischaemia but imposes a dependence on glycine clearance. Nature 520: 363-367, 2015.

126. Roberts E and Frankel S: Free amino acid in normal and neoplastic tissues of mice as studied by paper chromatography. Cancer Res 9: 645-648, 3 pl, 1949.

127. Roberts E and Borges PR: Patterns of free amino acids in growing and regressing tumor. Cancer Res 15: 697-699, 1955.

128. Yuneva M, Zamboni N, Oefner P, Sachidanandam R and Lazebnik Y: Deficiency in glutamine but not glucose induces MYC-dependent apoptosis in human cells. J Cell Biol 178: 93-105, 2007.

129. Wise DR, Deberardinis RJ, Mancuso A, Sayed N, Zhang XY, Pfeiffer HK, Nissim I, Daikhin E, Yudkoff M, McMahon SB, et al: Myc regulates a transcriptional program that stimulates mitochondrial glutaminolysis and leads to glutamine addiction. Proc Natl Acad Sci USA 105: 18782-18787, 2008

130. Gao P, Tchernyshyov I, Chang TC, Lee YS, Kita K, Ochi T, Zeller KI, De Marzo AM, Van Eyk JE, Mendell JT and Dang CV: c-Myc suppression of miR-23a/b enhances mitochondrial glutaminase expression and glutamine metabolism. Nature 458: 762-765, 2009.

131. Wang JB, Erickson JW, Fuji R, Ramachandran S, Gao P, Dinavahi R, Wilson KF, Ambrosio AL, Dias SM, Dang CV, et al: Targeting mitochondrial glutaminase activity inhibits oncogenic transformation. Cancer Cell 18: 207-219, 2010

132. Jin L, LI D, Alesi GN, Fan J, Kang HB, Lu Z, Boggon TJ, Jin P, Yi H, Wright ER, et al: Glutamate dehydrogenase1 signals through antioxidant glutathione peroxidasel to regulate redox homeostasis and tumor growth. Cancer Cell 27: 257-270, 2015.

133. Piskounova E, Agathocleous M, Murphy MM, Hu Z, Huddlestun SE, Zhao Z, Leitch AM, Johnson TM, DeBerardinis RJ and Morrison SJ: Oxidative stress inhibits distant metastasis by human melanoma cells. Nature 527: 186-191, 2015

134. Kung HN, Marks JR and Chi JT: Glutamine synthetase is a genetic determinant of cell type-specific glutamine independence in breast epithelia. PLoS Genet 7: e1002229, 2011.

135. Maher EA, Marin-Valencia I, Bachoo RM, Mashimo T, Raisanen J, Hatanpaa KJ, Jindal A, Jeffrey FM, Choi C, Madden C, et al: Metabolism of [ $\mathrm{U}^{13} \mathrm{C}$ ]glucose in human brain tumors in vivo. NMR Biomed 25: 1234-1244, 2012.

136. Guohua C, Stephanie L and Jian W: Glycine decarboxylase is a target for transcriptional repressor Snail. Cancer Metab 2 (Suppl 1): P83, 2014.

137. Lepage GA: In vitro incorporation of glycine-2- $\mathrm{C}^{14}$ into purines and proteins. Cancer Res 13: 178-185, 1953.

138. Zhang WC, Shyh-Chang N, Yang H, Rai A, Umashankar S, Ma S, Soh BS, Sun LL, Tai BC, Nga ME, et al: Glycine decarboxylase activity drives non-small cell lung cancer tumor-initiating cells and tumorigenesis. Cell 148: 259-272, 2012.

139. Shen T: Biochemistry. 2nd edition. Beijing, Higher Education Press, pp270-273, 1991.

140. Rose ML, Madren J, Bunzendahl H and Thurman RG: Dietary glycine inhibits the growth of B16 melanoma tumors in mice. Carcinogenesis 20: 793-798, 1999.

141. Kalhan SC and Hanson RW: Resurgence of serine: An often neglected but indispensable amino acid. J Biol Chem 287: 19786-19791, 2012

142. Possemato R, Marks KM, Shaul YD, Pacold ME, Kim D, Birsoy K, Sethumadhavan S, Woo HK, Jang HG, Jha AK, et al: Functional genomics reveal that the serine synthesis pathway is essential in breast cancer. Nature 476: 346-350, 2011.

143. Pipkorn R, Wiessler M, Waldeck W, Hennrich U, Nokihara K, Beining $M$ and Braun K: Improved synthesis strategy for peptide nucleic acids (PNA) appropriate for cell-specific fluorescence imaging. Int J Med Sci 9: 1-10, 2012

144. Lin J, Teo S, Lam DH, Jeyaseelan K and Wang S: MicroRNA-10b pleiotropically regulates invasion, angiogenicity and apoptosis of tumor cells resembling mesenchymal subtype of glioblastoma multiforme. Cell Death Dis 3: e398, 2012.

145. Gupta RA, Shah N, Wang KC, Kim J, Horlings HM, Wong DJ, Tsai MC, Hung T, Argani P, Rinn JL, et al: Long non-coding RNA HOTAIR reprograms chromatin state to promote cancer metastasis. Nature 464: 1071-1076, 2010.

146. Zhang C, Zhang Z, Zhu Y and Qin S: Glucose-6-phosphate dehydrogenase: A biomarker and potential therapeutic target for cancer. Anticancer Agents Med Chem 14: 280-289, 2014.
147. Wang R, Yu C, Zhao D, Wu M and Yang Z: The mucin-type glycosylating enzyme polypeptide $\mathrm{N}$-acetylgalactosaminyltran sferase 14 promotes the migration of ovarian cancer by modifying mucin 13. Oncol Rep 30: 667-676, 2013.

148. Li Y, Liu H, Huang YY, Pu LJ, Zhang XD, Jiang CC and Jiang ZW: Suppression of endoplasmic reticulum stress-induced invasion and migration of breast cancer cells through the downregulation of heparanase. Int J Mol Med 31: 1234-1242, 2013.

149. Lin RZ, Wang TP, Hung RJ, Chuang YJ, Chien CC and Chang HY: Tumor-induced endothelial cell apoptosis: Roles of NAD $(\mathrm{P}) \mathrm{H}$ oxidase-derived reactive oxygen species. J Cell Physiol 226: 1750-1762, 2011.

150. Qian YR, Guo Y, Wan HY, Fan L, Feng Y, Ni L, Xiang Y and Li QY: Angiotensin-converting enzyme 2 attenuates the metastasis of non-small cell lung cancer through inhibition of epithelial mesenchymal transition. Oncol Rep 29: 2408-2414, 2013.

151. Kim EK, Park JM, Lim S, Choi JW, Kim HS, Seok H, Seo JK, Oh K, Lee DS, Kim KT, et al: Activation of AMP-activated protein kinase is essential for lysophosphatidic acid-induced cell migration in ovarian cancer cells. J Biol Chem 286: 24036-24045, 2011.

152. Qiu SL, Xiao ZC, Piao CM, Xian YL, Jia LX, Qi YF, Han JH, Zhang YY and Du J: AMP-activated protein kinase $\alpha 2$ protects against liver injury from metastasized tumors via reduced glucose deprivation-induced oxidative stress. J Biol Chem 289: 9449-9459, 2014.

153. Skubitz AP, Taras EP, Boylan KL, Waldron NN, Oh S, Panoskaltsis-Mortari A and Vallera DA: Targeting CD133 in an in vivo ovarian cancer model reduces ovarian cancer progression. Gynecol Oncol 130: 579-587, 2013.

154. Chen J, Liu Q, Xiao J and Du J: EpCAM-antibody-labeled noncytotoxic polymer vesicles for cancer stem cells-targeted delivery of anticancer drug and siRNA. Biomacromolecules 16: 1695-1705, 2015.

155. Lawson DA, Bhakta NR, Kessenbrock K, Prummel KD, Yu Y, Takai K, Zhou A, Eyob H, Balakrishnan S, Wang CY, et al: Single-cell analysis reveals a stem-cell program in human metastatic breast cancer cells. Nature 526: 131-135, 2015.

156. Yang Y, Fan Y, Qi Y, Liu D, Wu K, Wen F and Zhao S: Side population cells separated from A549 Lung cancer cell line possess cancer stem cell-like properties and inhibition of autophagy potentiates the cytotoxic. Oncol Rep 34: 929-935, 2015.

157. Iacopino F, Angelucci C, Piacentini R, Biamonte F, Mangiola A, Maira G, Grassi C and Sica G: Isolation of cancer stem cells from three human glioblastoma cell lines: Characterization of two selected clones. PLoS One 9: e105166, 2014

158. Aguilar E, Marin de Mas I, Zodda E, Marin S, Morrish F, Selivanov V, Meca-Cortés Ó, Delowar H, Pons M, Izquierdo I, et al: Metabolic reprogramming and dependencies associated with epithelial cancer stem cells independent of the epithelial-mesenchymal transition program. Stem Cells 34: 1163-1176, 2016.

159. Mani SA, Guo W, Liao MJ, Eaton EN, Ayyanan A, Zhou AY, Brooks M, Reinhard F, Zhang CC, Shipitsin M, et al: The epithelial-mesenchymal transition generates cells with properties of stem cells. Cell 133: 704-715, 2008.

160. Visvader JE and Lindeman GJ: Cancer stem cells in solid tumors: Accumulating evidence and unresolved questions. Nat Rev Cancer 8: 755-768, 2008.

161. Oshimori N, Oristian D and Fuchs E: TGF- $\beta$ promotes heterogeneity and drug resistance in squamous cell carcinoma. Cell 160: 963-976, 2015 .

162. Gammon L, Biddle A, Heywood HK, Johannessen AC and Mackenzie IC: Sub-sets of cancer stem cells differ intrinsically in their patterns of oxygen metabolism. PLoS One 8: e62493, 2013.

163. Biddle A, Liang X, Gammon L, Fazil B, Harper LJ, Emich H, Costea DE and Mackenzie IC: Cancer stem cells in squamous cell carcinoma switch between two distinct phenotypes that are preferentially migratory or proliferative. Cancer Res 71: 5317-5326, 2011

164. Biddle A, Gammon L, Liang X, Costea DE and Mackenzie IC: Phenotypic plasticity determines cancer stem cell therapeutic resistance in oral squamous cell carcinoma. EBioMedicine 4: $138-145,2016$

165. Ying H, Kimmelman AC, Lyssiotis CA, Hua S, Chu GC, Fletcher-Sananikone E, Locasale JW, Son J, Zhang H, Coloff JL, et al: Oncogenic kras maintains pancreatic tumors through regulation of anabolic glucose metabolism. Cell 149: 656-670, 2012. 
166. ShiL, JackstadtR, Siemens H,Li H,KirchnerT and Hermeking H: p53-induced miR-15a/16-1 and AP4 form a double-negative feedback loop to regulate epithelial-mesenchymal transition and metastasis in colorectal cancer. Cancer Res 74: 532-542, 2014

167. Khew-Goodall Y and Goodall GJ: Myc-modulated miR-9 makes more metastases. Nat Cell Biol 12: 209-211, 2010.

168. Colvin H, Nishida N, Konno M, Haraguchi N, Takahashi H, Nishimura J, Hata T, Kawamoto K, Asai A, Tsunekuni K, et al: Oncometabolite D-2-hydroxyglurate directly induces epithelial-mesenchymal transition and is associated with distant metastasis in colorectal cancer. Sci Rep 8: 36289, 2016.

169. Kondoh H, Lleonart ME, Gil J, Wang J, Degan P, Peters G, Martinez D, Carnero A and Beach D: Glycolytic enzymes can modulate cellular life span. Cancer Res 65: 177-185, 2005.

170. Hu J, Liu Z and Wang X: Does TP53 mutation promote ovarian cancer metastasis to omentum by regulating lipid metabolism? Med Hypotheses 81: 515-520, 2013.

171. Paschka P, Schlenk RF, Gaidzik VI, Habdank M, Krönke J, Bullinger L, Späth D, Kayser S, Zucknick M, Götze K, et al: $I D H 1$ and $I D H 2$ mutations are frequent genetic alterations in acute myeloid leukemia and confer adverse prognosis in cytogenetically normal acute myeloid leukemia with $N P M 1$ mutation without FLT3 internal tandem duplication. J Clin Oncol 28 3636-3643, 2010.

172. Gaglio D, Metallo CM, Gameiro PA, Hiller K, Danna LS, Balestrieri C, Alberghina L, Stephanopoulos G and Chiaradonna F: Oncogenic K-Ras decouples glucose and glutamine metabolism to support cancer cell growth. Mol Syst Biol 7: $523,2011$.

173. Weinberg F, Hamanaka R, Wheaton WW, Weinberg S, Joseph J, Lopez M, Kalyanaraman B, Mutlu GM, Budinger GR and Chandel NS: Mitochondrial metabolism and ROS generation are essential for Kras-mediated tumorigenicity. Proc Natl Acad Sci USA 107: 8788-8793, 2010.

174. Guo JY, Chen HY, Mathew R, Fan J, Strohecker AM, Karsli-Uzunbas G, Kamphorst JJ, Chen G, Lemons JM, Karantza V, et al: Activated Ras requires autophagy to maintain oxidative metabolism and tumorigenesis. Genes Dev 25: 460-470, 2011.

175. Schwartzenberg-Bar-Yoseph F, Armoni M and Karnieli E: The tumor suppressor p53 down-regulates glucose transporters GLUT1 and GLUT4 gene expression. Cancer Res 64: 2627-2633, 2004.

176. Bensaad K, Tsuruta A, Selak MA, Vidal MN, Nakano K, Bartrons R, Gottlieb E and Vousden KH: TIGAR, a p53-inducible regulator of glycolysis and apoptosis. Cell 126: 107-120, 2006.

177. Matoba S, Kang JG, Patino WD, Wragg A, Boehm M, Gavrilova O, Hurley PJ, Bunz F and Hwang PM: p53 regulates mitochondrial respiration. Science 312: 1650-1653, 2006.

178. Li F, Wang Y, Zeller KI, Potter JJ, Wonsey DR, O'Donnell KA, Kim JW, Yustein JT, Lee LA and Dang CV: Myc stimulates nuclearly encoded mitochondrial genes and mitochondrial biogenesis. Mol Cell Biol 25: 6225-6234, 2005.

179. Smith AP, Verrecchia A, Fagà G, Doni M, Perna D, Martinato F, Guccione E and Amati B: A positive role for Myc in TGFbeta-induced Snail transcription and epithelial-to-mesenchymal transition. Oncogene 28: 422-430, 2009.
180. Lee SY, Jeon HM, Ju MK, Jeong EK, Kim CH, Park HG, Han SI and Kang HS: Dlx-2 and glutaminase upregulate epithelial-mesenchymal transition and glycolytic switch. Oncotarget 7: 7925-7939, 2016.

181. Liu W, Le A, Hancock C, Lane AN, Dang CV, Fan TW and Phang JM: Reprogramming of proline and glutamine metabolism contributes to the proliferative and metabolic responses regulated by oncogenic transcription factor c-Myc. Proc Natl Acad Sci USA 109: 8983-8988, 2012.

182. Kim JW, Gao P, Liu YC, Semenza GL and Dang CV: Hypoxiainducible factor 1 and dysregulated c-Myc cooperatively induce vascular endothelial growth factor and metabolic switches hexokinase 2 and pyruvate dehydrogenase kinase 1. Mol Cell Biol 27: 7381-7393, 2007

183. Zhao H, Duan Q, Zhang Z, Li H, Wu H, Shen Q, Wang C and Yin T: Up-regulation of glycolysis promotes the stemness and EMT phenotypes in gemcitabine-resistant pancreatic cancer cells. J Cell Mol Med 21: 2055-2067, 2017.

184. Guerra F, Guaragnella N, Arbini AA, Bucci C, Giannattasio S and Moro L: Mitochondrial dysfunction: A novel potential driver of epithelial-to-mesenchymal transition in cancer. Front Oncol 7: 295, 2017.

185. Murphy TA, Dang CV and Young JD: Isotopically nonstationary ${ }^{13} \mathrm{C}$ flux analysis of Myc-induced metabolic reprogramming in B-cells. Metab Eng 15: 206-217, 2013.

186. Yan H, Parsons DW, Jin G, McLendon R, Rasheed BA, Yuan W, Kos I, Batinic-Haberle I, Jones S, Riggins GJ, et al: IDHI and IDH2 mutations in gliomas. N Engl J Med 360: 765-773, 2009.

187. Dang L, White DW, Gross S, Bennett BD, Bittinger MA Driggers EM, Fantin VR, Jang HG, Jin S, Keenan MC, et al: Cancer-associated IDH1 mutations produce 2-hydroxyglutarate. Nature 462: 739-744, 2009

188. Ward PS, Patel J, Wise DR, Abdel-Wahab O, Bennett BD, Coller HA, Cross JR, Fantin VR, Hedvat CV, Perl AE, et al: The common feature of leukemia-associated IDH1 and IDH2 mutations is a neomorphic enzyme activity converting alpha-ketoglutarate to 2-hydroxyglutarate. Cancer Cell 17: 225-234, 2010

189. Turcan S, Rohle D, Goenka A, Walsh LA, Fang F, Yilmaz E, Campos C, Fabius AW, Lu C, Ward PS, et al: IDH1 mutation is sufficient to establish the glioma hypermethylator phenotype. Nature 483: 479-483, 2012

190. Figueroa ME, Abdel-Wahab O, Lu C, Ward PS, Patel J, Shih A, Li Y, Bhagwat N, Vasanthakumar A, Fernandez HF, et al: Leukemic IDH1 and IDH2 mutations result in a hypermethylation phenotype, disrupt TET2 function, and impair hematopoietic differentiation. Cancer Cell 18: 553-567, 2010.

191. Rohle D, Popovici-Muller J, Palaskas N, Turcan S, Grommes C, Campos C, Tsoi J, Clark O, Oldrini B, Komisopoulou E, et al: An inhibitor of mutant IDH1 delays growth and promotes differentiation of glioma cells. Science 340: 626-630, 2013.

192. Grassian AR,Lin F, Barrett R, Liu Y, Jiang W, Korpal M, Astley H, Gitterman D, Henley T, Howes R, et al: Isocitrate dehydrogenase (IDH) mutations promote a reversible ZEB1/microRNA (miR)-200-dependent epithelial-mesenchymal transition (EMT). J Biol Chem 287: 42180-42194, 2012. 